Research Article

\title{
Seed Proteomic Profiles of Three Paeonia Varieties and Evaluation of Peony Seed Protein as a Food Product
}

\author{
Xiuxia Ren $\mathbb{D}^{1},{ }^{1,2}$ Yantong Shi, ${ }^{3}$ Yuqian Xue, ${ }^{1,2}$ Jingqi Xue, ${ }^{1,2}$ Yuanyuan Tian, ${ }^{1,2}$ \\ Shunli Wang $\mathbb{D}^{1,2}$ and Xiuxin Zhang ${ }^{1,2,4}$ \\ ${ }^{1}$ Key Laboratory of Biology and Genetic Improvement of Horticultural Crops, Ministry of Agriculture and Rural Affairs, \\ Beijing, China \\ ${ }^{2}$ Institute of Vegetables and Flowers, Chinese Academy of Agricultural Sciences, Institute of Peony, Chinese Academy of \\ Agricultural Sciences, Beijing 100081, China \\ ${ }^{3}$ Beijing Agricultural Technology Extension Station, Beijing 100029, China \\ ${ }^{4}$ National Agricultural Science \& Technology Center, Chengdu, China
}

Correspondence should be addressed to Shunli Wang; shunliky@163.com and Xiuxin Zhang; zhangxiuxin@caas.cn

Xiuxia Ren, Yantong Shi, and Yuqian Xue contributed equally to this work.

Received 6 April 2020; Revised 21 July 2020; Accepted 18 August 2020; Published 20 November 2020

Academic Editor: Ernesto S. Nakayasu

Copyright (C) 2020 Xiuxia Ren et al. This is an open access article distributed under the Creative Commons Attribution License, which permits unrestricted use, distribution, and reproduction in any medium, provided the original work is properly cited.

Peony (Paeonia) has high ornamental, edible, and medicinal values. In order to distinguish seeds varieties, describe the proteomic profiles correlated with stress tolerance, and evaluate peony seed protein (PSP) as a functional food product, we characterized the seed protein profiles of these three species and their glucosidase inhibition activities. Results showed that the intensity of protein bands in sodium dodecyl sulfate polyacrylamide gel electrophoresis (SDS-PAGE) and specific protein ID (especially for specifically expressed proteins (SEPs)) was effective to distinguish these peony seed varieties. Proteomic analysis of the three species showed that P. ostii "Fengdan" has heat and pathogen tolerance-related proteins, while P. rockii has higher content of proteins related to cold resistance, which were all highly consistent with their adaptation of heat or cold habitat. Moreover, stress-related proteins were also accumulated in P. lactiflora Pall "Hangshao" seeds, showing its potential for stress resistance. Further protein analysis showed that the primary composition of PSP was albumin and globulin. And the solubility of PSP was good. Furthermore, PSP also showed high glucosidase inhibition activity, indicating that PSP might have some potential function for the remission of hyperglycemia. And P. ostii "Fengdan" seeds may be a better source for protein production than seeds of the other two species in terms of protein solubility and the content of total protein, albumin, and globulin. In addition, an optimal protocol of microwave-assisted alkali extraction was developed to produce PSP. In conclusion, the evaluated stress-related proteins in three peony seed species by proteomic analysis quite agreed with their adaptation of heat or cold stress; proteomics could also be a very useful tool for distinguishing species in the production; and peony seeds may be a good source for protein production.

\section{Introduction}

Peony is well known for its ornamental, medicinal, and edible properties, and it has become a commercial crop in China [1]. The economic benefit of peony is particularly increased by peony seed oil (PSO), which has more than $90 \%$ unsaturated fatty acids (UFAs) and more than $40 \% \alpha$-linolenic acid content [2]: Paeonia ostii "Fengdan" and P. rockii are the main species for the production of PSO [3, 4]. Moreover, high content of UFAs (more than 88.36\%) is also found in P. lactiflora Pall "Hangshao" seeds [5]. In addition to seed oil, there are many other nutritional and bioactive compounds in peony seeds, such as protein, phenolic compounds, monoterpene glycosides, $\gamma$-tocopherol, and paeoniflorin, which could be used in the production of health products and medicines [6]. 
High plant-protein diets contribute to weight control and have a significantly beneficial effect on cardiovascular disease [7]. Peony seed meal (the by-product of oil extraction) has high protein content (32.44\%) [2]. However, it is usually used as low value-added fertilizer or animal feed. It has been reported that PSP has favorable amino acid profiles and desirable physicochemical properties $[2,8]$. The essential amino acids of PSP account for $39.62 \%((E / T)$ essential amino acids to total amino acids), which is equal to soybean protein $(E / T, 39.33 \%)$ [9] and higher than FAO/WHO-suggested value $(E / T, 36.00 \%)$ [10]. The ratio $(63.86 \%)$ of the aromatic amino acids (tyrosine and phenylalanine) to the branched-chain amino acids (isoleucine, leucine, and valine) in PSP is much higher than that in soybean protein (49.72\%), suggesting that PSP could improve muscle metabolism and maintain protein homeostasis [11]. The low ratio $(0.25)$ of lysine to arginine in PSP may positively affect arginine uptake, which might help to prevent cardiovascular, atherogenic, and lipidemic disease [12]. Moreover, high content (18.48\%) of glutamic acid in PSP is useful for the regulation of glycogen synthesis and protein degradation, which is favorable for human health [13]. These results suggest that abundant amino acid composition in PSP plays an important role in regulating various physiological functions in the human body. Moreover, many $\alpha$-glucosidase inhibitors, such as peptides, glycosides, flavonoids, alkaloids, and terpenoids, have also been isolated from plants, including peony [14]. Natural sources containing $\alpha$-glucosidase inhibitors could be used to develop functional foods against diabetes. Therefore, the PSP could be used as a potential food ingredient with some beneficial functions and desirable properties [2].

Proteomic study is important for biological phenomena, developmental process, and metabolites synthesis. Some research on peony proteomics has been reported. Transcriptomic and proteomic analysis of $P$. ostii seeds was carried out to study the developmental stages and candidate genes related to oil biosynthesis and fatty acid metabolism [15]. Ren et al. [16] reported the mechanism of Paeonia ostii "Fengdan" seed germination as affected by low temperature using dynamic proteomic analysis. A quantitative proteomic analysis using isobaric tags for relative and absolute quantitation (iTRAQ) technology was performed on the stigma $24 \mathrm{~h}$ after pollination to better understand the molecular mechanisms involved in cross-incompatibility between tree peony (Paeonia ostii cv. Fengdanbai) and herbaceous peony (Paeonia lactiflora Pall. cv. Fenyunu) [17]. Zhao et al. [18] studied the mechanism of herbaceous peony in response to paclobutrazol inhibition of lateral branching using quantitative proteomics. Differential expression proteins have been studied during chilling treatment of tree peony (Paeonia suffruticosa) to illuminate the mechanism of bud dormancy release as affected by low temperature [19]. All those results show that proteomics is an important tool for the research of life sciences. Environmental factors in regional distribution or origin area greatly contribute to their differences in resistance [20]. P. ostii "Fengdan," $P$. rockii, and $P$. lactiflora Pall "Hangshao" are potential oil plants. Among which, P. ostii "Fengdan" originated from South China, $P$. rockii originated from North China, and the distribution of $P$. lactiflora Pall "Hangshao" plants is extensive. Thus, it is widely agreed that $P$. rockii has high cold tolerance, $P$. ostii "Fengdan" has strong ability to resist heat, wet, and pathogens, while P. lactiflora Pall "Hangshao" also has high resistance to temperature and pathogen stress due to its extensive distribution. Proteomics may help to explain the mechanism of cold and heat stress tolerance in these three peony species. Moreover, proteomic analysis is also useful for germplasm resource identification [20, 21]. Gliadins, low molecular weight glutenin subunits (LMW-GS), and high molecular weight glutenin subunits (HMW-GS) are reliable genetic markers for investigating diversity of wheat germplasms and their relatives [22, 23]. The stress resistance potential, selling price, and seed oil composition of $P$. ostii "Fengdan," $P$. rockii, and P. lactiflora Pall "Hangshao" are quite different [4]. Therefore, it is very important to make a germplasm resource identification system to avoid economic loss and uncertain quality problems caused by artificial adulteration. The current identification system of peony germplasms is focused on morphological characteristics, molecular markers [24], and microsatellites [25]. Proteomics has not been broadly used to study peony germplasms [8, 15-19]. Sodium dodecyl sulfate polyacrylamide gel electrophoresis (SDS-PAGE) and two-dimensional gel electrophoresis (2-DE) are two useful methods to separate and analyze proteins in proteomic research $[20,21]$.

In this study, the seed proteins from $P$. ostii "Fengdan," $P$. rockii, and $P$. lactiflora Pall "Hangshao" were first extracted and identified. Then, seed protein profiles of the three peony species were analyzed. The relationship between the stress resistance potential and protein profiles of the three peony species was also investigated. Finally, the glucosidase inhibition activity of PSP was studied and the processing technology for protein production was also optimized based on alkali and microwave-assisted extraction methods. The results of this study are significant for germplasm resource identification and PSP product development.

\section{Materials and Methods}

2.1. Materials. Seeds of $P$. ostii "Fengdan," $P$. rockii, and $P$. lactiflora Pall "Hangshao" were all collected from the peony germplasm resource nursery at the Institute of Vegetables and Flowers, Chinese Academy of Agricultural Sciences, in 2016. Seeds of $P$. ostii "Fengdan," P. rockii, and P. lactiflora Pall "Hangshao" were collected from 30 plants at random, and fully mixed seeds were selected to do the experiment.

\subsection{Measurement of Morphological Parameters and Nutrition} Components of Seeds. A total of 90 seeds were separated into three groups and used to measure longitudinal and transverse diameters. Fresh weight was determined using 300 seeds with three repetitions. The water content, soluble sugar content, and starch content were measured according to the method of Ren et al. [16]. Crude protein content was determined according to the Chinese national standard for the determination of crude protein in oil plants $(\mathrm{GB} / \mathrm{T}$ 14489.2-2008). Fatty acid was extracted and determined according to the method of Wei et al. [26]. 
2.3. Extraction and Separation of Albumins, Globulins, Gliadins, Glutenins, and Total Proteins in One-Way SDS$P A G E$. Albumins, globulins, gliadins, and glutenins in oneway SDS-PAGE analysis were extracted using double-distilled water $\left(\mathrm{ddH}_{2} \mathrm{O}\right), 0.5 \mathrm{M}$ sodium chloride $(\mathrm{NaCl}), 70 \%$ ethanol, or $0.1 \mathrm{M}$ potassium hydroxide, respectively. Albumins were removed from extracts during globulin extraction, while albumins and globulins were removed during gliadin extraction. Albumins, globulins, and gliadins were removed during glutenin extraction. The SDS-PAGE analysis followed the instructions of Wang et al. [23]. Samples were loaded on SDS-PAGE with (b1, b3, b5, and b7) or without (b2, b4, b6, and b8) denaturation $\left(65^{\circ} \mathrm{C}\right.$ thermostatic water bath).

Total protein was extracted using a saturated phenol method by one-way SDS-PAGE analysis with some modification. Briefly, total proteins were extracted using the Tris-saturated phenol and a lysis buffer containing $0.5 \mathrm{M}$ Tris- $\mathrm{HCl}$ ( $\mathrm{pH}$ 7.5), $0.7 \mathrm{M}$ sucrose, $0.1 \mathrm{M}$ potassium chloride, $0.05 \mathrm{M}$ ethylenediaminetetraacetic acid (EDTA), and 2\% $\beta$-mercaptoethanol. The phenol phase was collected after centrifugation at $12,000 \mathrm{rpm}\left(4^{\circ} \mathrm{C}\right)$ for $10 \mathrm{~min}$ and precipitated in $0.1 \mathrm{M}$ ammonium acetate methanol solution (5 times the volume of the extracts) at $-20^{\circ} \mathrm{C}$ for 12 hours. The protein precipitate was collected after centrifugation at $12,000 \mathrm{rpm}$ $\left(4^{\circ} \mathrm{C}\right)$ for $5 \mathrm{~min}$ and washed using precooled methanol and acetone. The protocol of SDS-PAGE analysis was according to the description of Wang et al. [23]. Samples were loaded on SDS-PAGE with (b1, b3, b5, and b7) or without (b2, b4, $\mathrm{b} 6$, and $\mathrm{b} 8$ ) denaturation.

2.4. Protein Extraction, Separation, and Identification in 2$D E$ Analysis. Protein separation and identification in 2-DE analysis were conducted as described before [16]. Total protein was extracted with buffer A $(1 \mathrm{M} \mathrm{pH} 7.5$ Tris- $\mathrm{HCl}, 0.1 \mathrm{M}$ EDTA, $0.25 \mathrm{M}$ sucrose, $1 \mathrm{mM}$ PMSF, and $1 \mathrm{mM}$ DTT) and buffer B (1 M pH 7.5 Tris-HCl, 0.1 M EDTA, $0.25 \mathrm{M}$ sucrose, $4 \%$ Triton-100, $1 \mathrm{mM}$ PMSF, and $1 \mathrm{mM}$ DTT) according to the method described before $[8,27]$. After centrifugation at $13,000 \mathrm{rpm}$ and $4^{\circ} \mathrm{C}$ for $10 \mathrm{~min}$, the supernatant was precipitated by $50 \%$ TCA buffer at $-20^{\circ} \mathrm{C}$ for 3 hours. The precipitate was washed three times with chilled acetone containing DTT. The pellet was dried and dissolved in lysis buffer containing $7 \mathrm{M}$ urea, $2 \mathrm{M}$ thiourea, and 4\% CHAPS. At last, protein concentrations were measured using a 2-D Quant Kit (Amersham Biosciences, USA) and BSA was used as the standard. Briefly, $5 \mu \mathrm{l}$ protein solution was mixed with $500 \mu \mathrm{l}$ precipitant and $500 \mu \mathrm{l}$ coprecipitant, respectively, and followed by a quick vortex. After centrifugation at $13,000 \mathrm{rpm}$ for $5 \mathrm{~min}$, the super-

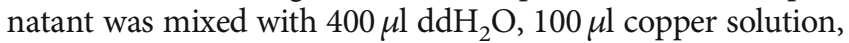
and the working color solution ( color A : color $\mathrm{B}=100: 1$ ). The fluorescence was measured at $480 \mathrm{~nm}$, and protein concentration was calculated based on the BSA standard curve. The same amount of protein sample $(600 \mu \mathrm{g}$ protein) from every peony species mixed with $0.5 \%$ IPG buffer, rehydration buffer (8M urea, $2 \%$ CHAPS), $1 \%(w / v)$ DTT, and $1 \mu \mathrm{l} 1 \%$ bromophenol blue was loaded onto an the IEF linear IPG strips (pH 3-10NL, $18 \mathrm{~cm}$, GE Healthcare) and rehydrated using an $\mathrm{Ettan}^{\mathrm{TM}}$ IPGphor ${ }^{\mathrm{TM}}$ II. Isoelectric focusing was performed under the following conditions: $300 \mathrm{~V}$ for 1 hour,
$500 \mathrm{~V}$ for 1 hour, $1000 \mathrm{~V}$ for 1 hour, $3000 \mathrm{~V}$ for 1 hour, and finally run at $8000 \mathrm{~V}$ for $80 \mathrm{kVh}$. After focusing, the strips were equilibrated twice in equilibration solution, and then, proteins were separated on $12 \%$ SDS-polyacrylamide gels. Protein spots were stained using Coomassie brilliant blue (CBB, R-250/G-250) and scanned at 600 dpi with a BIORAD GS-800 scanner. Differentially expressed protein (DEP) spots were figured out based on statistically significant differences between samples from three peony species using Student's $t$-test (abundance variation of at least 2 -fold, $p<0.05$ ) by an ImageMaster ${ }^{\mathrm{TM}}$ 2D Platinum Software (Amersham Biosciences).

The spots of interest were excised from gels and subjected to a destaining solution ( $30 \% \mathrm{ACN}$ with $100 \mathrm{mM} \mathrm{NH}_{4} \mathrm{HCO}_{3}$ ). The gel pieces were lyophilized and rehydrated in $50 \mathrm{mM}$ $\mathrm{NH}_{4} \mathrm{HCO}_{3}$ solution (containing $50 \mathrm{ng}$ trypsin). The peptides were then extracted twice using $0.1 \%$ trifluoroacetic acid (TFA) in $50 \%$ acetonitrile (ACN). The extracts were pooled together and lyophilized. Peptide mixtures were redissolved in $0.1 \%$ TFA and mixed with $\alpha$-cyano-4-hydroxycinnamic acid in $30 \% \mathrm{ACN}$ and $0.1 \%$ TFA before spotting onto the target plate. Protein identification was performed on an $A B$ SCIEX MALDI TOF-TOF 5800 Analyzer (AB SCIEX, Foster City, CA, USA). Mass maps were acquired in positive ion reflector mode with 1000 laser shots per spectrum. The PMF peak detection criteria used were a minimum $S / N$ of 10 , local noise window width mass/charge $(\mathrm{m} / \mathrm{z})$ of 250 , and minimum full-width half-maximum (bins) of 2.9. A maximum of 15 precursors per spot with a minimum signal/noise ratio of 50 were selected for MS/MS analysis. The contaminant $\mathrm{m} / \mathrm{z}$ peaks were excluded from MS/MS analysis. An energy level of $2 \mathrm{kV}$ was used for the collision-induced dissociation, with 3000 acquisitions accumulated for each MS/MS spectrum. A combined MS and MS/MS search was performed against the NCBI nr database for Malus. All automatic data analysis and database searches were conducted using GPS Explorer ${ }^{\mathrm{TM}}$ (ver. 3.6, $\mathrm{AB}$ SCIEX) running a Mascot search algorithm (v2.3, Matrix Science, London, UK) for protein identification. The raw MS and MS/MS spectra were processed using GPS Explorer ${ }^{\mathrm{TM}}$ software. The searches were conducted using the following settings: trypsin as the digestion enzyme, one missed cleavage, $100 \mathrm{ppm}$ precursor tolerance, MS/MS ion tolerance of $0.6 \mathrm{Da}$, and methionine oxidation as the variable modification. Proteins with protein score confidence intervals $>95 \%$ (protein score $>60$ ) were considered as confident identifications. The identified proteins were then matched to specific processes or functions by searching Gene Ontology (http:// www.geneontology.org/). Transcript information and chloroplast genomic data for Paeonia species are included in the plant genetic and proteomic bank. Our identified proteins were blasted and matched to these sequences in the plant genetic and proteomic bank.

2.5. Analysis of Protein Solubility and Glucosidase Inhibition Activity and Optimization of the Protein Extraction Process. Sample powder was fully mixed with distilled water to a solid-liquid ratio of $1: 30$. The temperature of the water bath was about $55^{\circ} \mathrm{C}$, and $\mathrm{pH}$ was adjusted to 10.0 . Alkaline protease with 10 times the volume of the protein powder was 
added. Enzymatic hydrolysis was stopped after $20 \mathrm{~min}$, $40 \mathrm{~min}, 80 \mathrm{~min}, 150 \mathrm{~min}$, and $400 \mathrm{~min}$. Protein at different periods of enzymatic hydrolysis was fully mixed with distilled water and centrifuged at $5000 \mathrm{rpm}$ for $20 \mathrm{~min}$. The degree of protein hydrolysis was measured according to Nielsen et al. [28]. The nitrogen solubility index was equivalent to the amount of protein in the supernatant divided by the amount of protein in the stock solution.

About $5 \mathrm{~g}$ of sample powder was fully mixed with distilled water to a solid-liquid ratio of $1: 35$. Then, $\mathrm{pH}$ was adjusted to 10.5 . Microwave power and time was set as $280 \mathrm{~W}$ and 150 s, respectively. About $10 \%$ alkaline protease was continuously added to the homogenized mixtures. Protein was hydrolyzed at $55^{\circ} \mathrm{C}$ for 3 hours with a $\mathrm{pH}$ of 10 . The enzyme was inactivated at $100^{\circ} \mathrm{C}$ for $5 \mathrm{~min}$. Supernatant was collected after centrifugation for further determination. The content of peptides was determined using the biuret method.

The inhibition rate of $\alpha$-glucosidase was measured as follows. Samples, $0.05 \mathrm{M}$ phosphate buffer solution (PBS), enzyme solution, and $\mathrm{p}$-nitrophenyl- $\alpha$-D-glucopyranoside (PNPG) (the detailed information is listed in Supplementary Table S1) were mixed together and reacted at $37^{\circ} \mathrm{C}$ in a water bath for $15 \mathrm{~min}$. The reaction was terminated with a sodium carbonate solution. Absorbance was measured at $405 \mathrm{~nm}$. The inhibition rate of $\alpha$-glucosidase was determined according to the following formula. Inhibition rate $=\left(A_{1}-\left(A_{2}-A_{4}\right)\right) /\left(A_{1}-A_{3}\right)$, where $A_{1}, A_{2}$, $A_{3}$, and $A_{4}$ were the absorbances corresponding to the control group, the measurement group, the blank group, and the background group, respectively.

To improve the protein extraction process, a single-factor experiment and an $L_{9}\left(3^{4}\right)$ orthogonal experiment was carried out. Factors of the extraction process are shown in Supplementary Tables S2 and S3. No microwave treatment (microwave time is zero) was used as the control. Seeds were ground in a disintegrator (IKA, Guangzhou, China), and the powder was sieved using a 200-mesh sieve with a diameter of $450 \mu \mathrm{m}$. The dry powder $(10 \mathrm{~g})$ was homogenized with deionized water (solid-liquid ratio $(\mathrm{g} / \mathrm{ml})$ ranging from $1: 25$ to $1: 45$ ), and $\mathrm{pH}$ was adjusted to $9.5-11.5$. The supernatant was collected after centrifugation at $5000 \mathrm{rpm}$ for $20 \mathrm{~min}$. A microwave oven (Shunde, Guangdong, China) with $1000 \mathrm{~W}$ power was used in the extraction step. The supernatant was put in a microwave oven for $0-150 \mathrm{~s}$ at $210-490 \mathrm{~W}$. Protein content was determined according to Ren et al. [16].

\section{Results}

3.1. Measurement of the Morphological Parameters and Physiological Characteristics of the Seeds of Three Peony Species. The seed surface of tree peony (P. ostii "Fengdan" and $P$. rockii) was very smooth, bright, and shiny black, and the shape of tree peony seeds was round and full, whereas the seed surface of herbaceous peony ( $P$. lactiflora Pall "Hangshao") was a little rough in dark brown and its shape was not very full (Figure 1(a)). The longitudinal diameter of three peony seeds was slightly longer than the transverse diameter, and the longitudinal to transverse diameter ratio was about 1.2 (Figure 1(b)). The transverse diameter of $P$. rockii seeds was around $9.0 \mathrm{~mm}$, the transverse diameter of $P$. ostii "Fengdan" seeds was about $8.0 \mathrm{~mm}$, and the transverse diameter of $P$. lactiflora Pall "Hangshao" seeds was approximately $7.0 \mathrm{~mm}$ (Figure $1(\mathrm{~b})$ ). The longitudinal diameter of $P$. rockii and $P$. ostii "Fengdan" seeds was about $10 \mathrm{~mm}$, which was significantly bigger than that of $P$. lactiflora Pall "Hangshao" seeds (8 mm) (Figure 1(b)). Water content was increased in $P$. ostii "Fengdan" seeds $(8.71 \%)$ compared to $P$. rockii (8.21\%) and P. lactiflora Pall "Hangshao" seeds (8.08\%) (Table 1). Biomass (fresh weight) of $P$. rockii seeds $(0.30 \mathrm{~g})$ was the greatest, and $P$. ostii "Fengdan" seeds $(0.26 \mathrm{~g})$ also increased in biomass over P. lactiflora Pall "Hangshao" seeds (0.21 g) (Table 1$)$.

Soluble sugar content was the highest in P. lactiflora Pall "Hangshao" seeds (10.87\%), followed by $P$. rockii seeds (9.49\%), and it was the lowest in P. ostii "Fengdan" seeds $(8.61 \%)$ (Table 1). Starch content was enhanced in P. lactiflora Pall "Hangshao" (10.46\%) and P. rockii seeds (10.16) over that of $P$. ostii "Fengdan" seeds (7.44\%). There was much more protein in P. ostii "Fengdan" seeds (20.7\%) compared with P. rockii (18.9\%) and P. lactiflora Pall "Hangshao" (16.5\%) seeds. Total fatty acid content was significantly higher in P. lactiflora Pall "Hangshao" seeds (16.8\%) than in $P$. rockii $(11.5 \%)$ and $P$. ostii "Fengdan" (10.3\%) seeds. And protein content was the greatest among four basic nutrient compositions.

3.2. Analysis of Albumins, Globulins, Gliadins, Glutenins, and Total Proteins Using One-Way SDS-PAGE. Albumins, globulins, gliadins, and glutenins with or without $65^{\circ} \mathrm{C}$ denaturation pretreatment were analyzed by one-way SDS-PAGE (Figure 2(a)). The bands of albumins, globulins, and glutenins were somewhat improved using $65^{\circ} \mathrm{C}$ denaturation, suggesting that a pretreatment of $65^{\circ} \mathrm{C}$ denaturation should be used for SDS-PAGE analysis. The size of albumins, globulins, and glutenins was about $8-120 \mathrm{kDa}, 20-94 \mathrm{kDa}$, and 10 $94 \mathrm{kDa}$, respectively. The number of albumin bands was the most, the color was the darkest, and the bands were clearest (Figure 2(a)); the bands of globulins were also very clear, but at a weaker intensity than those of albumins (Figure 2(a)); and the bands of gliadins and glutenins were very blurry, especially those of gliadins (Figure 2(a)). Consistently, the content of albumins was the highest (at $54 \%$ of the total), followed by globulins (21\%) and glutenins (19\%), and the content of gliadins was the lowest $(6 \%)$ in $P$. ostii "Fengdan" seeds (Figure 2(b)).

The albumin, globulin, and total protein separation in $P$. ostii "Fengdan," P. rockii, and P. lactiflora Pall "Hangshao" seeds is shown in Figures 2(c)-2(e). The size of albumins was about $8-120 \mathrm{kDa}$ in $P$. ostii "Fengdan" and $P$. rockii seeds, while it ranged from 20 to $94 \mathrm{kDa}$ in $P$. lactiflora Pall "Hangshao" seeds (Figure 2(c)). The number of albumin bands was the greatest in $P$. ostii "Fengdan" seeds, followed by $P$. rockii seeds, and there were only three bands in $P$. lactiflora Pall "Hangshao" seeds. The size of globulins was about $20-94 \mathrm{kDa}$ in $P$. ostii "Fengdan" and $P$. rockii seeds, while it was 20 to $40 \mathrm{kDa}$ in P. lactiflora Pall "Hangshao" seeds (Figure 2(d)). The number and intensity of globulin bands were the highest in P. ostii "Fengdan" seeds, followed 


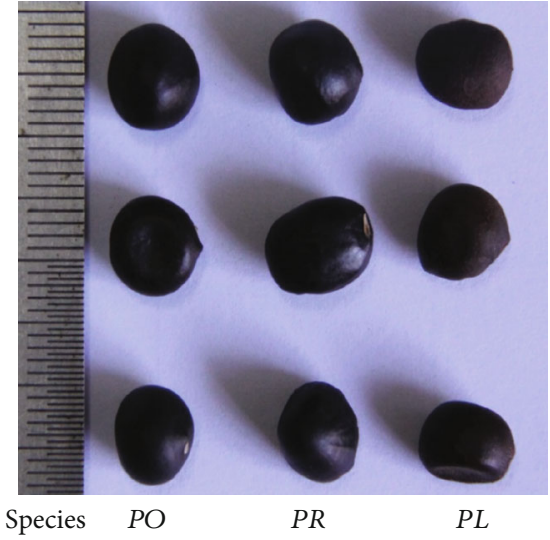

(a)

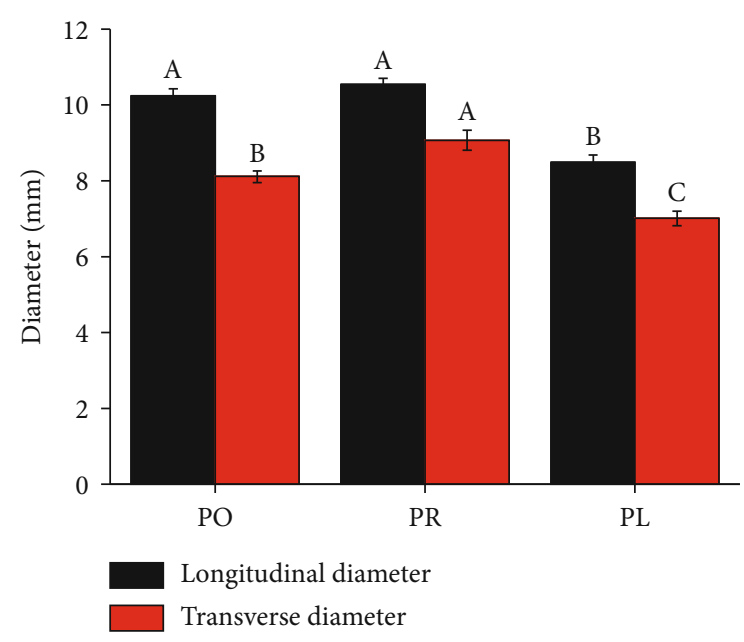

(b)

FIgure 1: (a) Morphology and (b) longitudinal and transverse diameter of P. ostii "Fengdan" (PO), P. rockii (PR), and P. lactiflora Pall "Hangshao" (PL) seeds.

TAble 1: Morphological and physiological parameters of Paeonia ostii “Fengdan," P. rockii, and P. lactiflora Pall "Hangshao" seeds.

\begin{tabular}{|c|c|c|c|c|c|c|}
\hline Species & $\begin{array}{c}\text { Water content } \\
(\%)\end{array}$ & $\begin{array}{l}\text { Fresh weight } \\
\text { (g) }\end{array}$ & $\begin{array}{l}\text { Soluble sugar content } \\
(\%)\end{array}$ & $\begin{array}{c}\text { Starch content } \\
(\%)\end{array}$ & $\begin{array}{c}\text { Protein content } \\
(\%)\end{array}$ & $\begin{array}{c}\text { Total fatty acid } \\
\text { content }(\%)\end{array}$ \\
\hline $\begin{array}{l}\text { P. ostii } \\
\text { "Fengdan" }\end{array}$ & $8.71 \pm 0.02 \mathrm{a}$ & $0.26 \pm 0.005 b$ & $8.61 \pm 0.11 \mathrm{c}$ & $7.44 \pm 0.07 \mathrm{~b}$ & $20.7 \pm 0.43 \mathrm{a}$ & $10.3 \mathrm{~b}$ \\
\hline P. rockii & $8.21 \pm 0.12 \mathrm{~b}$ & $0.30 \pm 0.003 \mathrm{a}$ & $9.49 \pm 0.05 b$ & $10.16 \pm 0.28 \mathrm{a}$ & $18.9 \pm 0.30 \mathrm{~b}$ & $11.5 \mathrm{~b}$ \\
\hline $\begin{array}{l}\text { P. lactiflora Pall } \\
\text { "Hangshao" }\end{array}$ & $8.08 \pm 0.07 \mathrm{~b}$ & $0.21 \pm 0.002 \mathrm{c}$ & $10.87 \pm 0.28 \mathrm{a}$ & $10.46 \pm 0.15 a$ & $16.5 \pm 0.47 c$ & $16.8 \mathrm{a}$ \\
\hline
\end{tabular}

Significant separation within treatments was assayed by an analysis of variance (ANOVA) and Duncan's multiple range tests at the $5 \%$ level.

by $P$. rockii seeds, and they were the lowest in $P$. lactiflora Pall "Hangshao" seeds. There were only two blurry globulin bands (about $20 \mathrm{kDa}$ and $40 \mathrm{kDa}$ ) in P. lactiflora Pall "Hangshao" seeds. The size of total protein bands in P. ostii "Fengdan," P. rockii, and P. lactiflora Pall "Hangshao" seeds was about 8-100 kDa, 23-94 kDa, and 14-66 kDa, respectively (Figure 2(e)). The greatest number and highest intensity of total protein bands were also found in P. ostii "Fengdan" seeds, followed by P. lactiflora Pall "Hangshao" seeds. Overall, the primary proteins were albumin and globulin in peony seed, and the greatest content of albumin, globulin, and total protein was all found in $P$. ostii "Fengdan" seeds.

3.3. Protein Identification and Expression Analysis. The specifically expressed proteins (SEPs) and differentially expressed proteins (DEPs) are annotated in Figures 3(a)3(c) with different colors. A total of 61 proteins were identified from P. ostii "Fengdan," P. rockii, and P. lactiflora Pall "Hangshao" seeds (Table 2). Among these 61 proteins, eight, two, and two SEPs were only identified from $P$. ostii "Fengdan," P. rockii, and P. lactiflora Pall "Hangshao" seeds, respectively. And there were 49 DEPs shared among the seeds of all three species. All those proteins were widely distributed in a range of $\mathrm{pH}$ 3-10. Gene Ontology analysis were assigned to DEPs and divided into nine groups, including carbohydrate metabolism (17\%), proteometabolism and amino acid metabolism (14\%), lipid metabolism (4\%), stress related (17\%), hormone-related metabolism (12\%), signaling and transport proteins (4\%), nucleic acid metabolism (10\%), other proteins (10\%), and unassigned proteins (12\%) (Figure 3(d)). Two SEPs (34 and 38) identified from P. rockii seeds were both stress related (Figure 4(a)). One SEP (16) identified from $P$. lactiflora Pall "Hangshao" seeds was carbohydrate metabolism related and the other (45) one from $P$. lactiflora Pall "Hangshao" seeds was unassigned (Figure 4(a)). Among the eight SEPs identified from P. ostii "Fengdan" seeds, two (47 and 50) were proteometabolism and amino acid metabolism related, two (46 and 52) were nucleic acid metabolism related, one (51) was carbohydrate metabolism related, one (53) was stress related, one (54) was lipid metabolism related, and one (49) was unassigned (Figure 4(a)).

The expression patterns of the 38 important DEPs were divided into three clusters: (1) Cluster I, including 28 DEPs that were highly enhanced in P. ostii "Fengdan" seeds, most of these proteins (85.7\%) were the lowest in P. lactiflora Pall "Hangshao" seeds; (2) Cluster II, including two DEPs that were the highest in $P$. rockii seeds, followed by P. ostii "Fengdan" seeds; and (3) Cluster III, including eight DEPs that were highly accumulated in $P$. lactiflora Pall "Hangshao" seeds, followed by $P$. ostii "Fengdan" seeds (Figure 4(b)). 


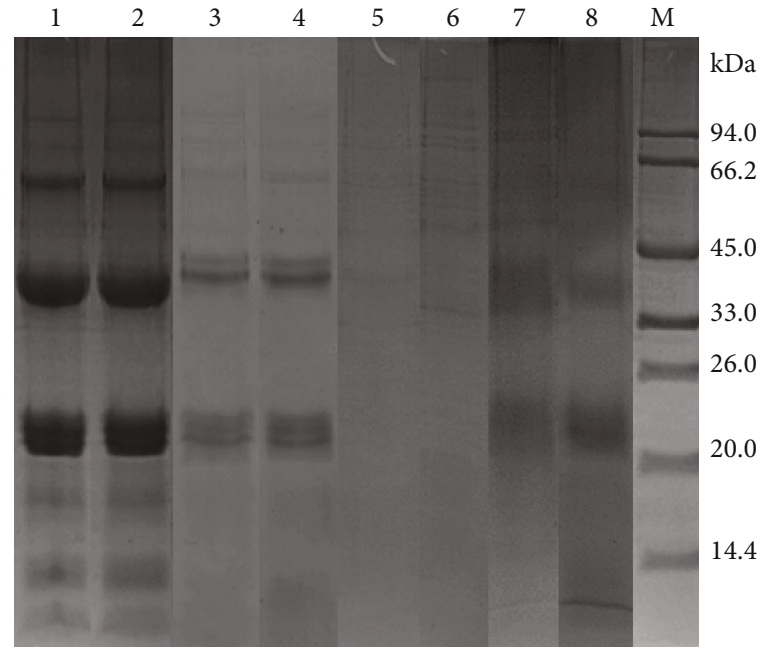

(a)

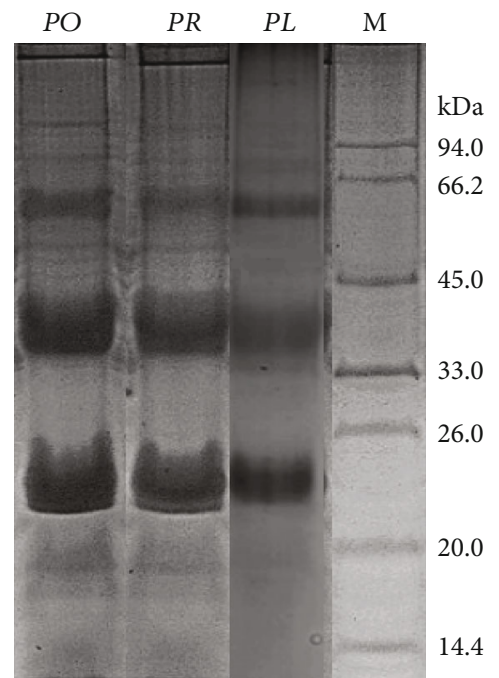

(c)

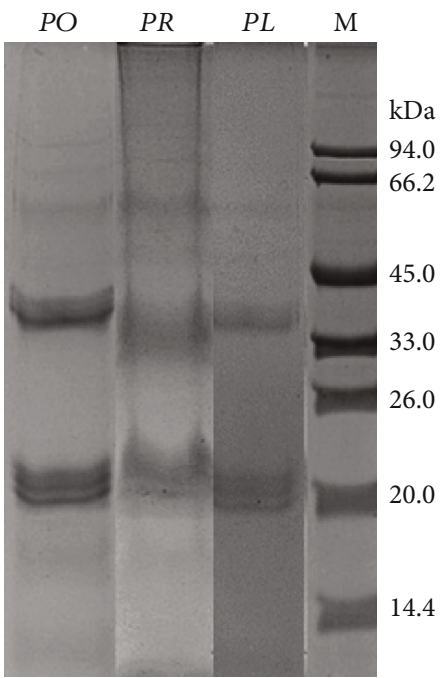

(d)

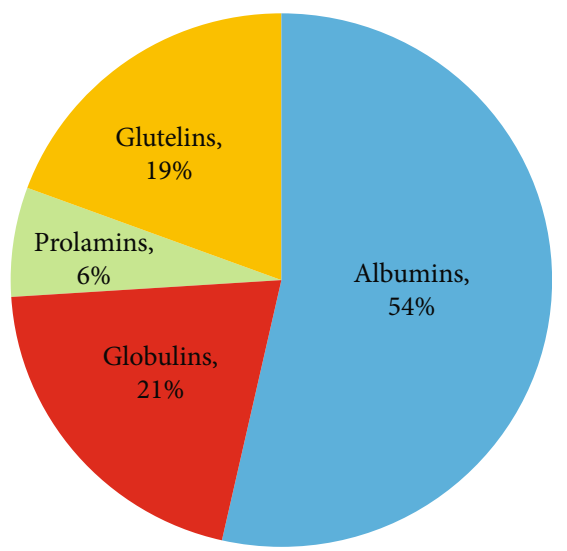

(b)

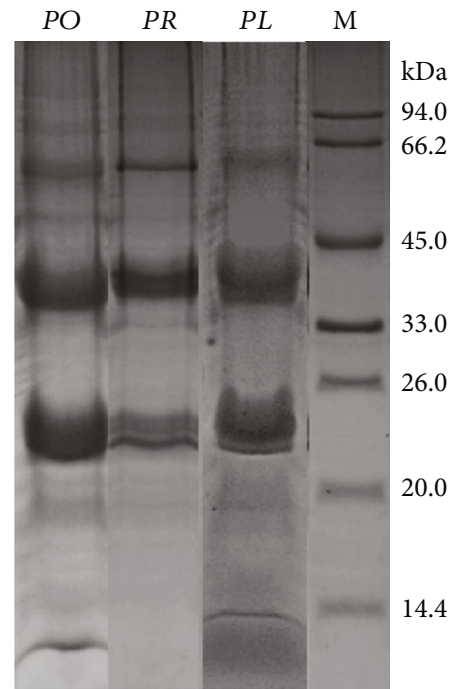

(e)

FIgure 2: (a) Comparison of albumin, globulin, gliadin, and glutenin pretreatment with or without $65^{\circ} \mathrm{C}$ denaturation using SDS-PAGE analysis, (b) ratio of these protein fractions to total proteins, and SDS-PAGE analysis of (c) albumins, (d) globulins, and (e) total proteins extracted from seeds of three peony species. a-1: albumin, 2-ME/SDS buffer, $65^{\circ} \mathrm{C}$ water bath extraction, and $65^{\circ} \mathrm{C}$ denaturation; a-2: albumin, 2-ME/SDS buffer, $65^{\circ} \mathrm{C}$ water bath extraction, and room temperature; a-3: globulin, $2-\mathrm{ME} / \mathrm{SDS}$ buffer, $65^{\circ} \mathrm{C}$ water bath extraction, and $65^{\circ} \mathrm{C}$ denaturation; a-4: globulin, 2-ME/SDS buffer, $65^{\circ} \mathrm{C}$ water bath extraction, and room temperature; a-5: gliadin, 2-ME/SDS buffer, $65^{\circ} \mathrm{C}$ water bath extraction, and $65^{\circ} \mathrm{C}$ denaturation; a-6: gliadin, $2-\mathrm{ME} / \mathrm{SDS}$ buffer, $65^{\circ} \mathrm{C}$ water bath extraction, and room temperature; a-7: glutelin, 2-ME/SDS buffer, $65^{\circ} \mathrm{C}$ water bath extraction, and $65^{\circ} \mathrm{C}$ denaturation; and a-8: glutelin, 2-ME/SDS buffer, $65^{\circ} \mathrm{C}$ water bath extraction, and room temperature. M: protein marker.

3.4. Analysis of Protein Solubility. The degree of protein hydrolysis and solubility were determined at $0,10,20,40$, 80,150 , and $400 \mathrm{~min}$ after hydrolysis. In general, both degree of protein hydrolysis and nitrogen solubility index (NSI) were the highest in proteins extracted from P. ostii "Fengdan" seeds, followed by those extracted from $P$. rockii seeds (Figures 5(a) and 5(b)). After hydrolysis for $400 \mathrm{~min}$, the hydrolysis degree of PSP ranged between $58.4 \%$ and $61.2 \%$, and NSI of PSP was about 34.6\%-42.3\%.

3.5. Analysis of Glucosidase Inhibition Activity. To verify the glucosidase inhibition activity of PSP, peptides were extracted from seeds of $P$. ostii "Fengdan," $P$. rockii, and $P$. lactiflora Pall
"Hangshao," and the content of peptide and their glucosidase inhibition ratios were estimated. Results showed that the activity of $\alpha$-glucosidase was reduced remarkably by the addition of peony seed peptides. The peptide content in seed protein of three peony species was $18.2 \%-20.4 \%$, while the glucosidase inhibition rate was 22.6\%-25.7\% (Figures 5(c) and 5(d)). Peptide content and glucosidase inhibition rate were not significantly different among the three peony species. Based on the degree of hydrolysis, protein solubility, and glucosidase inhibition rate, $P$. ostii "Fengdan" seeds were a better choice for developing high-value protein products with good hydrolysis and dissolution characteristics and a desirable glucosidase inhibition activity. 


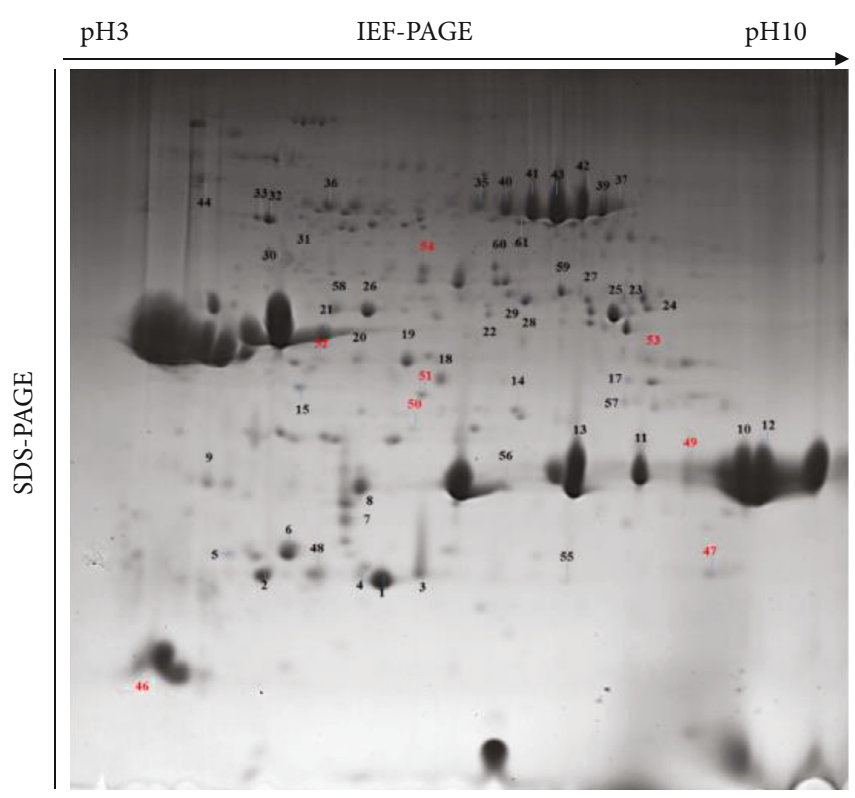

(a)

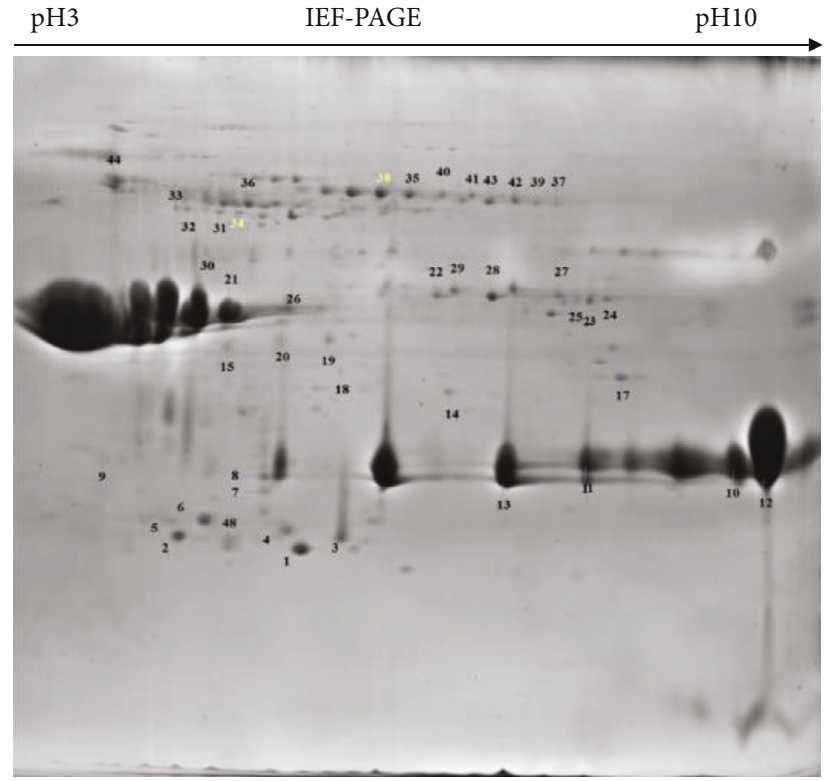

(b)

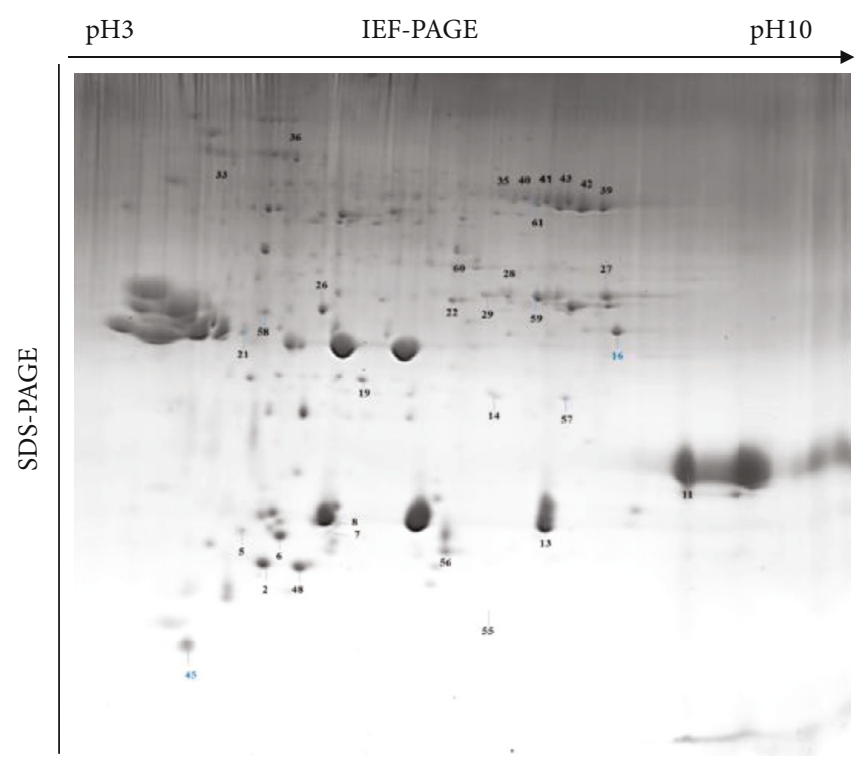

(c)

Figure 3: Continued. 


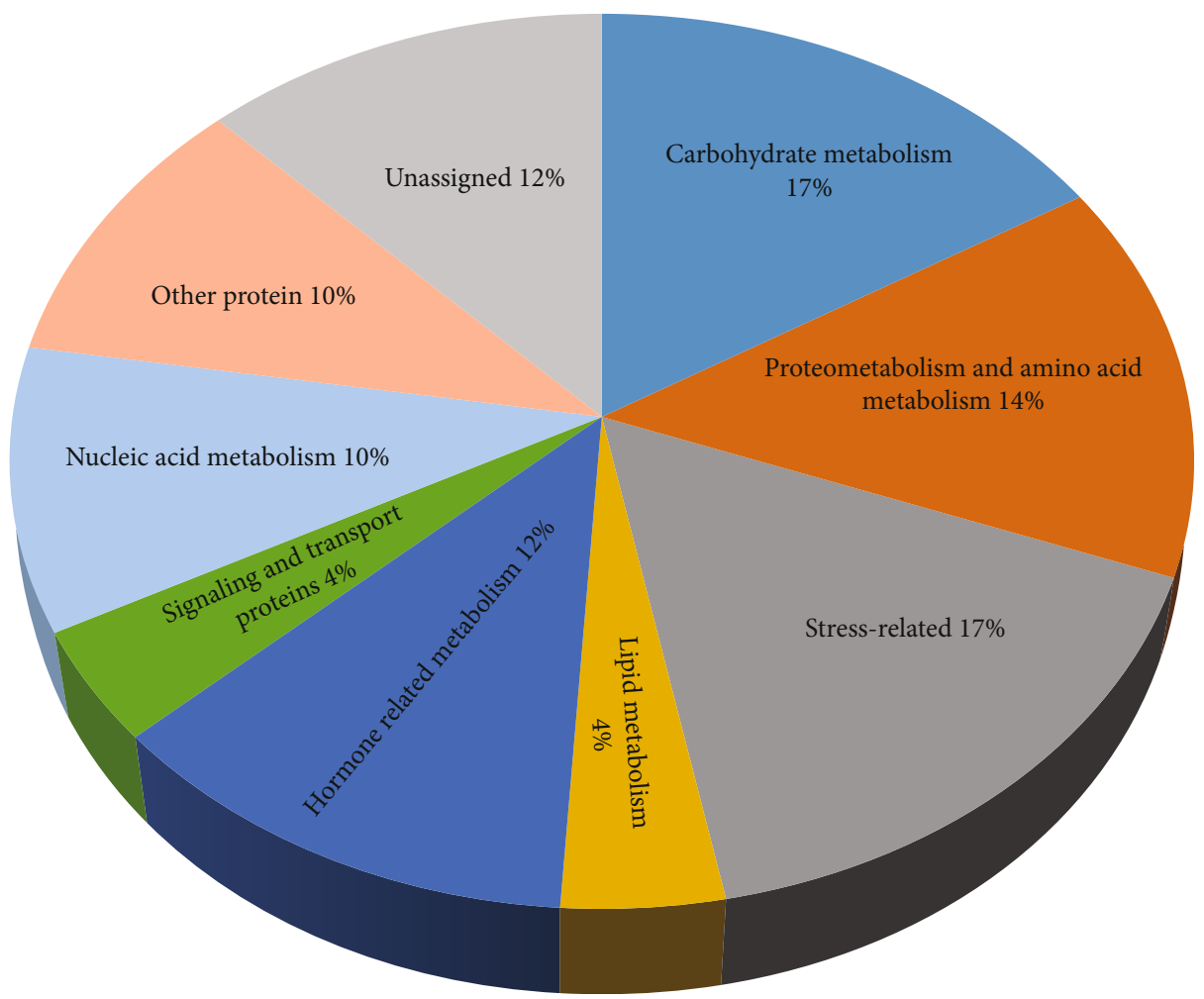

(d)

Figure 3: Proteome maps of total proteins from (a) P. ostii "Fengdan," (b) P. rockii, and (c) P. lactiflora Pall "Hangshao" seeds and (d) gene ontology analysis of differentially expressed proteins (DEPs). Same amount of protein sample (600 $\mu \mathrm{g}$ protein) from every peony seed species was loaded onto the IEF linear IPG strips to make sure that same amount of protein was analyzed. The SEPs in $P$. ostii "Fengdan", $P$. rockii, and P. lactiflora Pall seeds are marked with red, yellow, and blue, respectively.

3.6. Optimization of the Protein Extraction Process. A singlefactor experiment and an $L_{9}\left(3^{4}\right)$ orthogonal methodology experiment were carried out to optimize the protein extraction process (Supplementary Tables S2 and S3). The extraction solid-liquid ratio, $\mathrm{pH}$, microwave time, and microwave power had great effect on protein extraction efficiency. Protein extraction efficiency was first increased as the solid-liquid ratio increased and peaked at a solid-liquid ratio of 1:35 (Figure 6(a)). After that, it decreased with an increase in the solid-liquid ratio. For the $\mathrm{pH}$ of the protein extraction process, protein content increased from $\mathrm{pH} 9.5$ to $\mathrm{pH} 11.0$ and then decreased when $\mathrm{pH}$ was higher than 11.0 (Figure 6(b)). Microwave-assisted protein extraction significantly increased the protein content. Protein extraction efficiency was the greatest with $120 \mathrm{~s}$ of microwaving (Figure 6(c)). For microwave power, protein content increased first, then decreased, and finally increased again to reach a maximum at $490 \mathrm{~W}$ (Figure 6(d)). Above all, the single-factor experiment showed that protein extraction efficiency was the greatest with a solid-liquid ratio of $1: 35$, a $\mathrm{pH}$ of 11.0 , and $120 \mathrm{~s}$ of microwaving at $490 \mathrm{~W}$. Moreover, the results of the $L_{9}\left(3^{4}\right)$ orthogonal methodology experiment showed that the optimum conditions were solid-liquid ratio of $1: 35$, microwave power at 280, microwave time of $120 \mathrm{~s}$, and $\mathrm{pH}$ at 10.5 (Table 3).

\section{Discussion}

Recently, the components of peony seeds have become a focus of attention. The high content of unsaturated fatty acids (UFAs), protein, and secondary metabolites found in the peony seeds may greatly contribute to their favorable medicinal and nutritional characteristics $[1,2,16]$. PSP is considered to be a potential food ingredient due to its satisfactory amino acid composition and beneficial functions [2]. Moreover, proteomics is an important tool for the study of biological phenomena and germplasm resource identification. Quality problems caused by artificial adulteration of seeds were becoming serious in commercial peony seed production and their processed products. Therefore, it is necessary to establish peony germplasm identification methods, study the protein profiles, and evaluate the physicochemical and functional characteristics of the extracted PSP.

4.1. Analysis of Basic Nutrient Composition of Seeds. Seeds are important storage organs in nature that provide nutrition for embryo development and germination. Seeds of angiosperms are always rich in oil, starch, and protein. Four kinds of basic nutrient components, including proteins, starch, soluble sugar, and fatty acids, have been detected in peony seeds. Of these, crude protein content was the highest, which was 


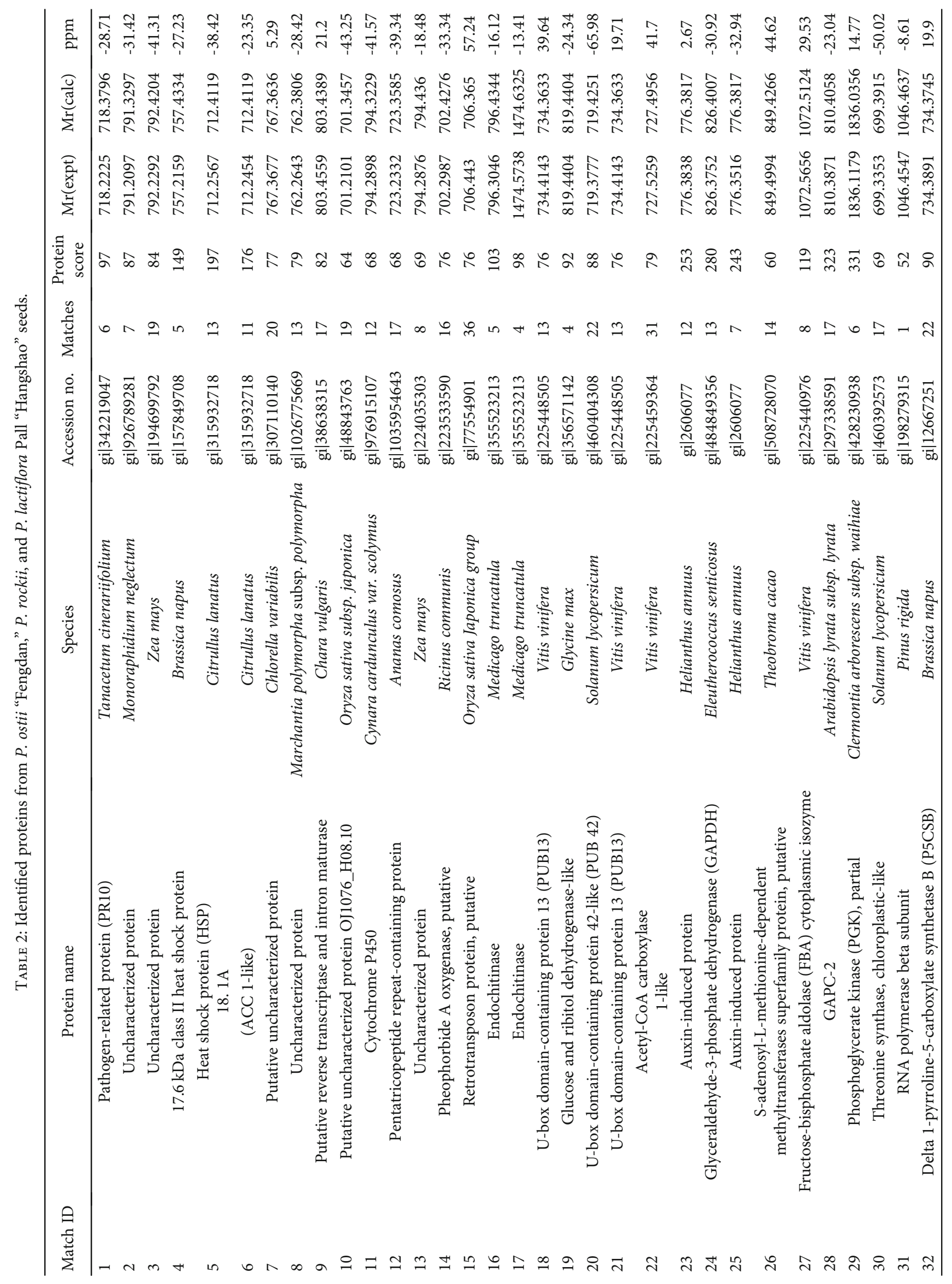




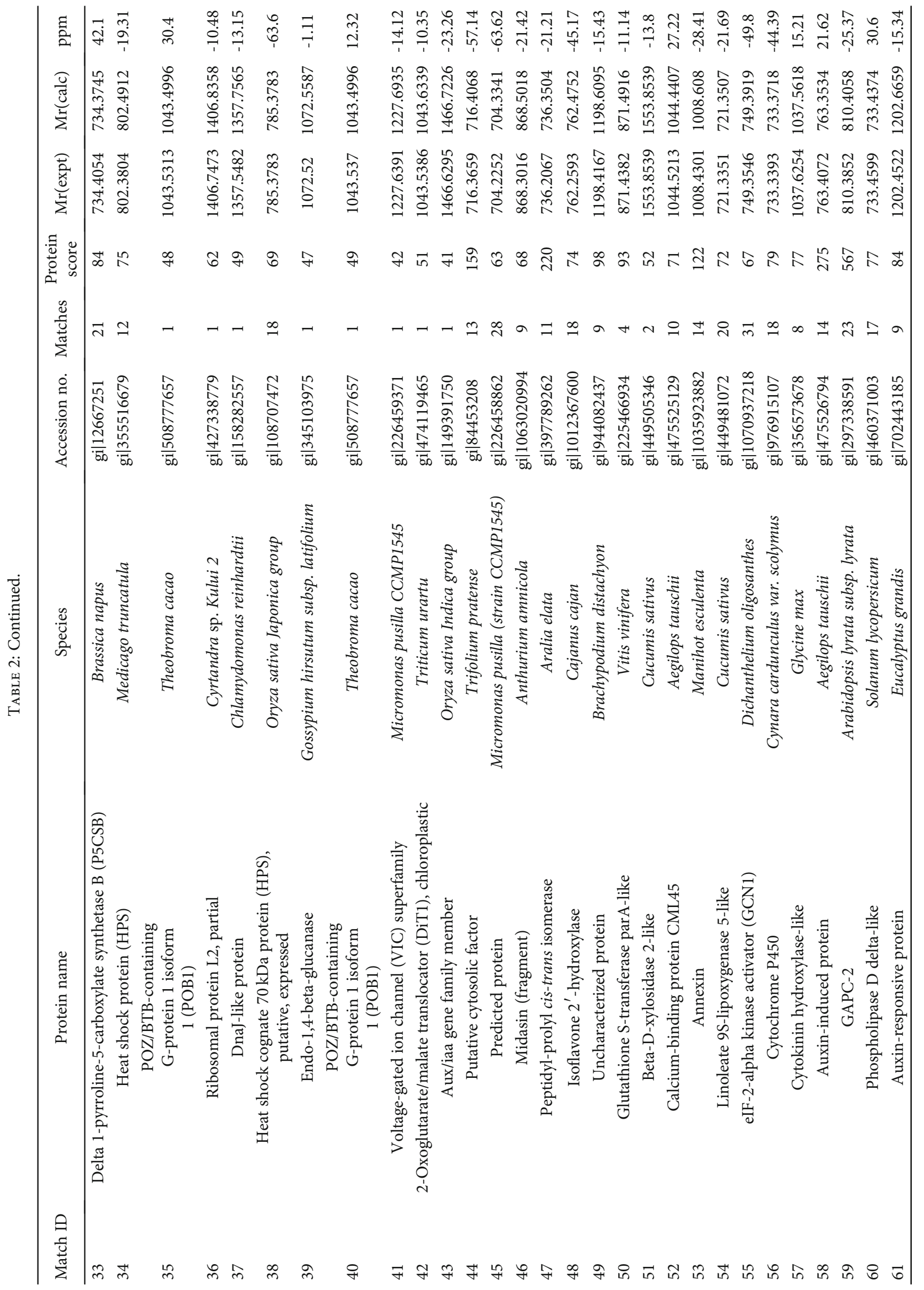



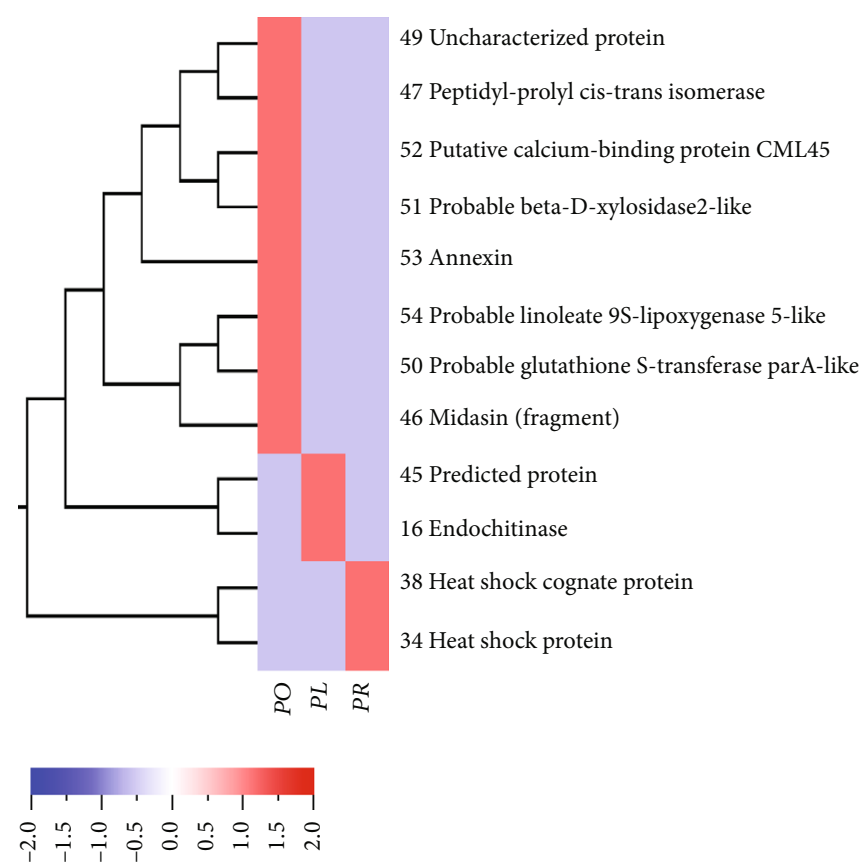

(a)

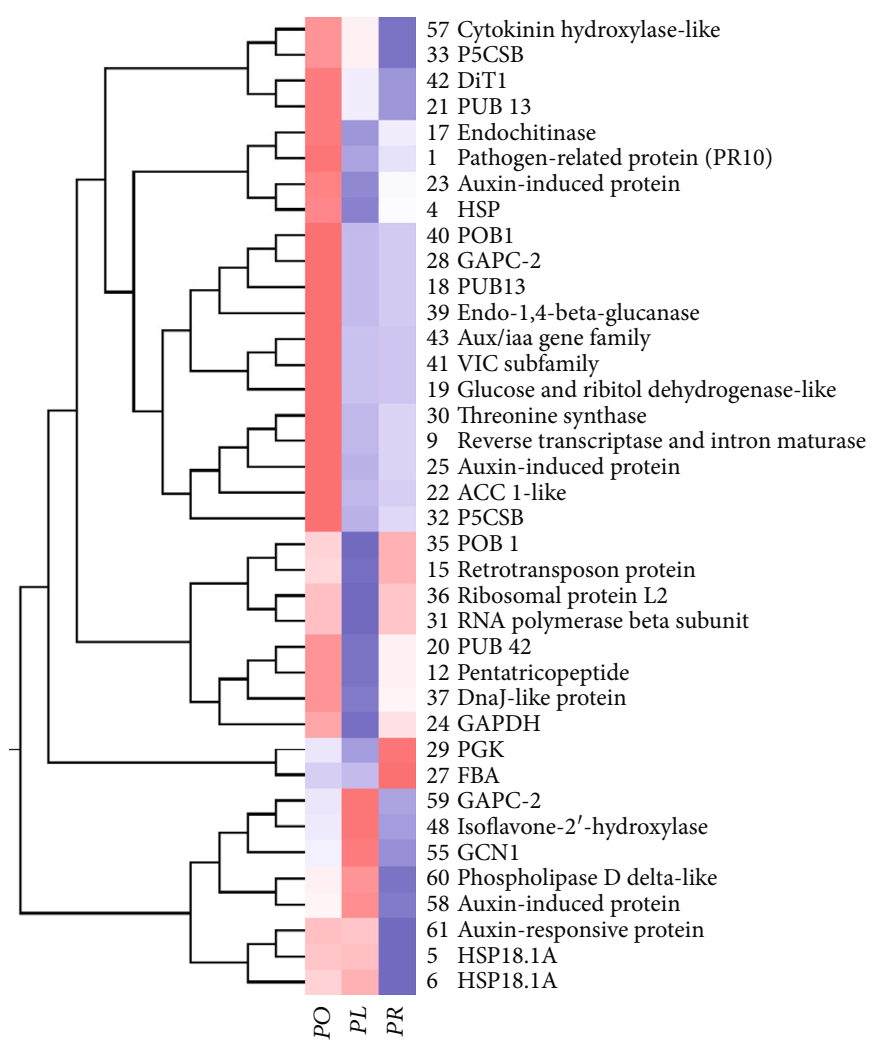

(b)

FIGURE 4: Hierarchical clustering analysis of (a) specifically expressed proteins (SEPs) and (b) DEPs of three peony species. Abbreviations: P5CSB: delta 1-pyrroline-5-carboxylate synthetase B; DiT1: 2-oxoglutarate/malate translocator; PUB13: U-box domain-containing protein 13; PR10: pathogen-related protein; HPS: heat shock protein; POB1: POZ/BTB-containing G-protein 1 isoform 1; GAPC-2: glyceraldehyde-3-phosphate dehydrogenase 2; PUB13: U-box domain-containing protein 13; VIC: voltage-gated ion channel superfamily; ACC 1-like: acetyl-CoA carboxylase 1-like; PUB 42: U-box domain-containing protein 42-like; GAPDH: glyceraldehyde-3-phosphate dehydrogenase; PGK: phosphoglycerate kinase; FBA: fructose-bisphosphate aldolase, cytoplasmic isozyme; GCN1: eIF-2-alpha kinase activator; HSP18.1A: heat shock protein 18.1A. 


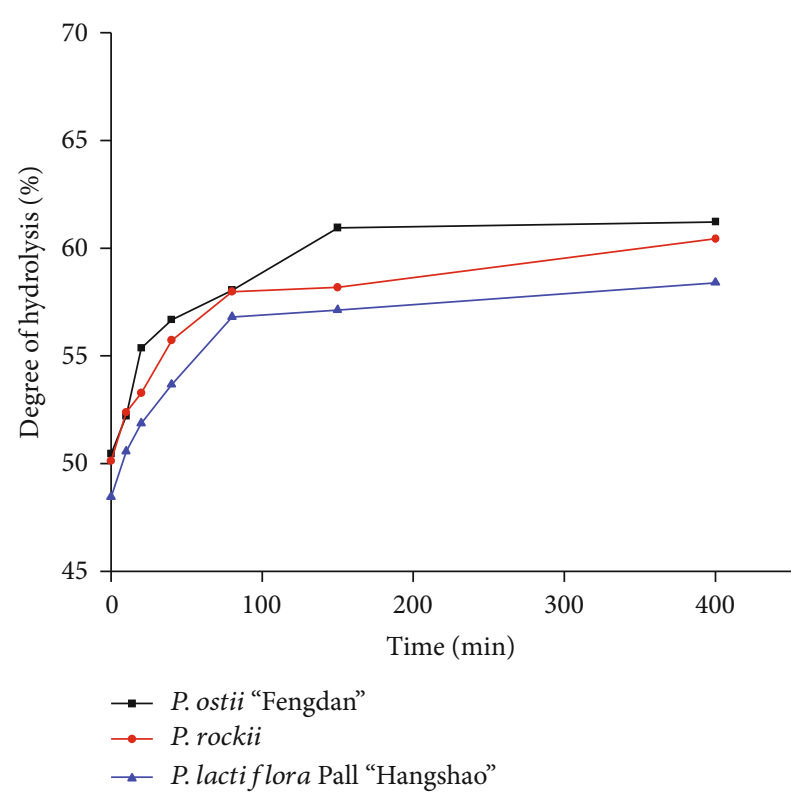

(a)

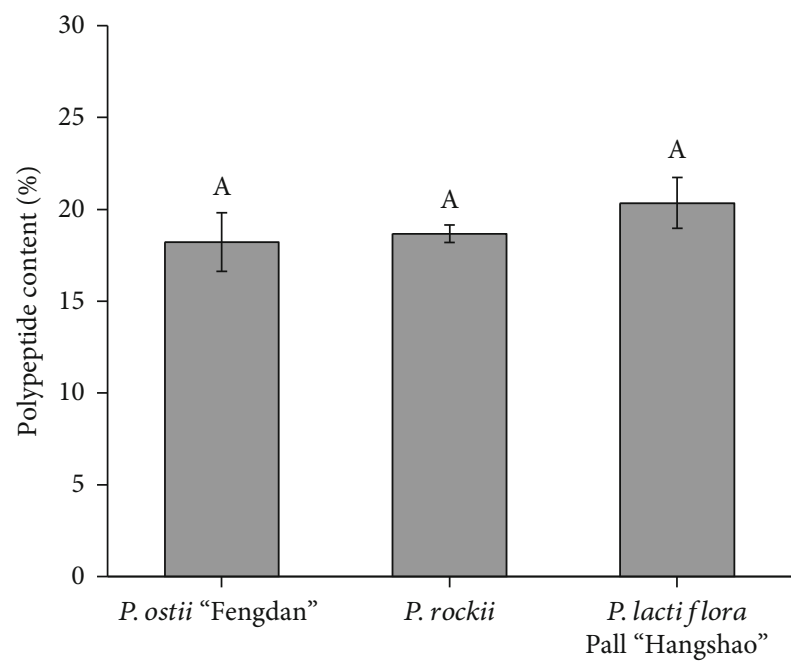

(c)

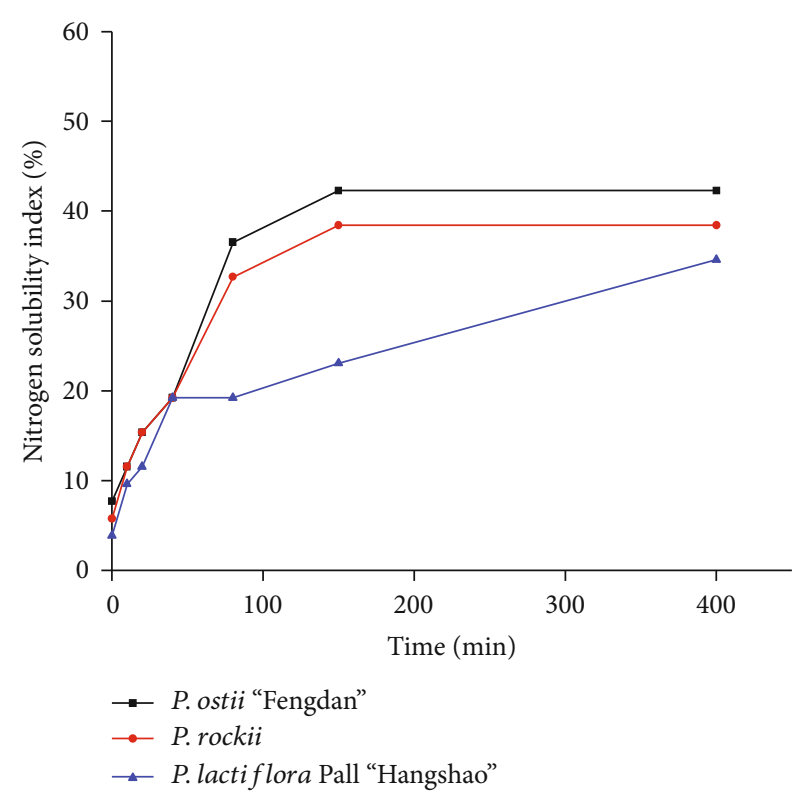

(b)

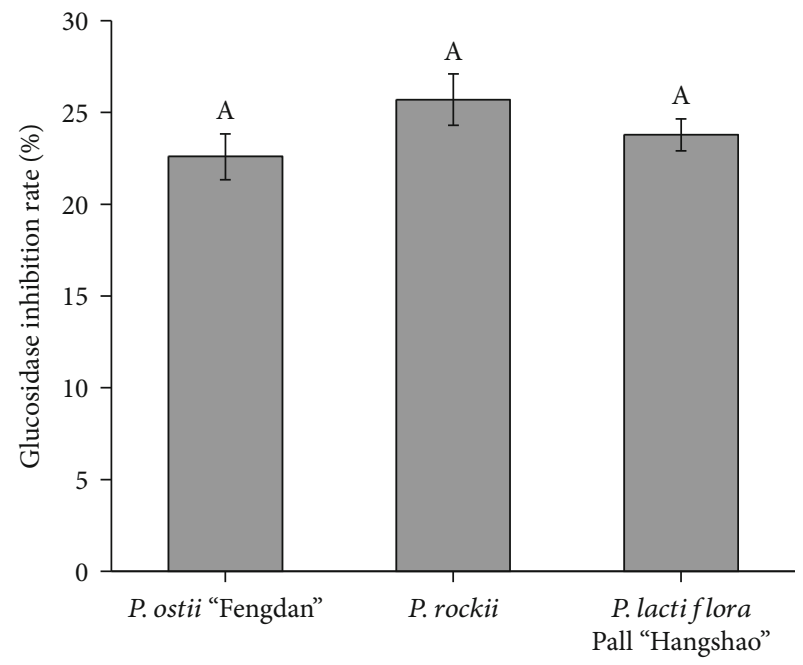

(d)

Figure 5: (a) Degree of hydrolysis, (b) nitrogen solubility index, (c) peptide content, and (d) glucosidase inhibition rate of proteins extracted from P. ostii "Fengdan," P. rockii, and P. lactiflora Pall "Hangshao" seeds. Significant separation within treatments was assayed by an analysis of variance (ANOVA) and Duncan's multiple range tests at the $5 \%$ level.

significantly higher than the content of fatty acids and starch. The nutritional compositions of peony seeds were consistent with Cucurbita maxima seeds [29]. The highest level of crude protein was detected in $P$. ostii "Fengdan" seeds, followed by $P$. rockii seeds. Encouragingly, seed protein content from all these three peony species was greater than that from wheat seeds, the leading source of vegetal protein in human food [30], suggesting the advantages and potential of peony seeds, especially for P. ostii "Fengdan" seeds, in protein product development.

4.2. Peony Germplasm Resource Identification by One-Way $S D S-P A G E$ and SEPs in 2-DE. Accurate and rapid laboratory techniques for germplasm resource identification are becoming increasingly important for protecting the rights and interests of consumers and ensuring quality and safety of commercial food product. There is always artificial adulteration of peony seeds (most commonly, mixed seeds from different peony species) on the peony market due to rough production methods and profit-driven system, which greatly reduced the quality of seed products, such as peony seed oil and PSP. To identify and avoid artificial adulteration of peony seeds, we developed two strategies: SDS-PAGE could distinguish the mixed tree and herbaceous peony seeds effectively; SEPs in 2-DE could be used as protein markers to identify seeds of these three peony species on the market. In general, tree ( $P$. ostii "Fengdan" and $P$. rockii) and herbaceous ( $P$. lactiflora Pall "Hangshao") peony seeds could be roughly distinguished by color and seed size (Figure 1), which should be verified by scientific technology method. 


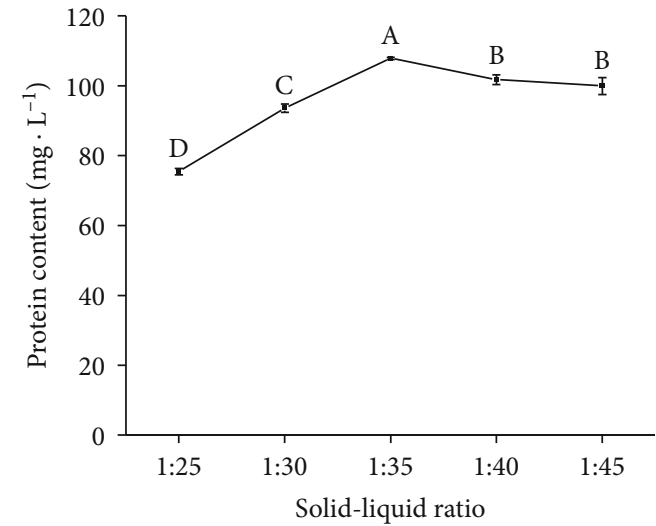

(a)

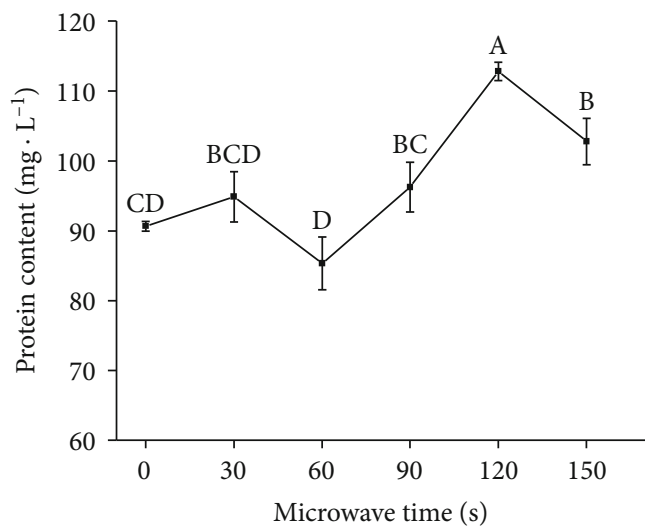

(c)

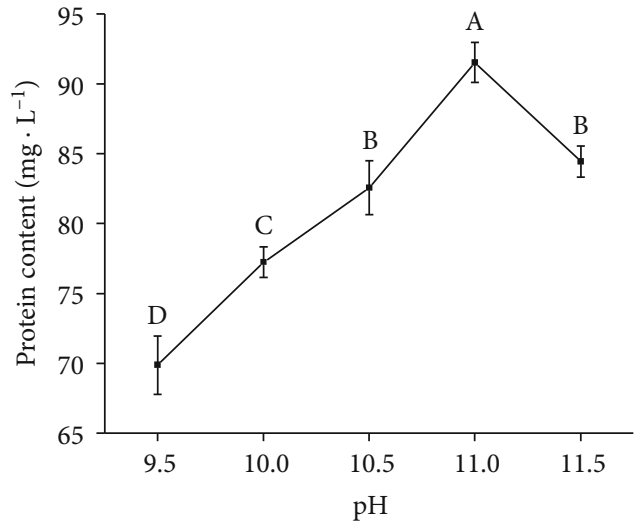

(b)

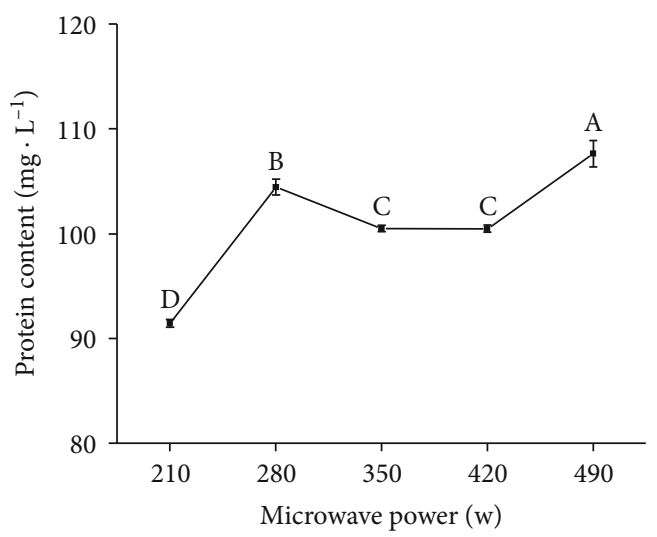

(d)

Figure 6: Protein content as affected by (a) solid-liquid ratio, (b) $\mathrm{pH}$, (c) microwave time, and (d) microwave power in a single-factor experiment.

TABLE 3: Content of protein as affected by solid-liquid ratio, microwave power, microwave time, and extraction $\mathrm{pH}$ in a $L_{9}\left(3^{4}\right)$ orthogonal experiment.

\begin{tabular}{|c|c|c|c|c|c|}
\hline Test no. & Solid-liquid ratio $(m: v)$ & Microwave power $(\mathrm{W})$ & Microwave time (s) & Extraction $\mathrm{pH}$ & Protein content $(\mathrm{mg} / \mathrm{g})$ \\
\hline 1 & $1(1: 30)$ & $1(210)$ & $1(90)$ & $1(10.5)$ & 89.94 \\
\hline 2 & 1 & $2(280)$ & $2(120)$ & $2(11)$ & 92.36 \\
\hline 3 & 1 & $3(350)$ & $3(150)$ & $3(11.5)$ & 99.58 \\
\hline 4 & $2(1: 35)$ & 1 & 2 & 3 & 98.47 \\
\hline 5 & 2 & 2 & 3 & 1 & 103.39 \\
\hline 6 & 2 & 3 & 1 & 2 & 89.23 \\
\hline 7 & $3(1: 40)$ & 1 & 3 & 2 & 101.41 \\
\hline 8 & 3 & 2 & 1 & 3 & 95.64 \\
\hline 9 & 3 & 3 & 2 & 1 & 94.13 \\
\hline $\mathrm{K} 1$ & 281.88 & 289.82 & 274.81 & 287.46 & \\
\hline K2 & 291.09 & 291.39 & 284.96 & 283 & \\
\hline K3 & 291.18 & 282.94 & 304.38 & 293.69 & \\
\hline $\mathrm{R}$ & 9.3 & 8.45 & 29.57 & 10.69 & \\
\hline
\end{tabular}

In this study, SDS-PAGE was effective to distinguish the mixed tree and herbaceous peony seeds: the bands of albumins and globulins were much more obvious in $P$. ostii "Fengdan" and P. rockii seeds than in P. lactiflora Pall "Hang- shao" seeds (Figure 2). Moreover, protein markers developed from 2-DE-based proteomics are widely used in plants to assess genetic variability [31]. A 2-DE-based dynamic proteomic technique could be used to distinguish $P$. ostii 
"Fengdan" and P. rockii seeds. Most SEPs were highly expressed in P. ostii "Fengdan" seeds, and the number of SEPs was also the greatest in P. ostii "Fengdan" seeds. All in all, seeds of P. ostii "Fengdan," P. rockii, and P. lactiflora Pall "Hangshao" can be easily distinguished by SEPs: there were eight SEPs $(46,47,49,50,51,52,53$, and 54) in P. ostii "Fengdan" seeds, two SEPs (34 and 38 ) in $P$. rockii seeds, and two SEPs (16 and 45) in P. lactiflora Pall "Hangshao" seeds. Those SEPs could be used as protein markers to identify seeds of these three peony species on the market and in the production. Other proteins, such as LMW-GS and HMWGS are also developed as reliable genetic markers for investigating diversity of wheat germplasms [22, 23]. Therefore, SDS-PAGE and 2-DE technique could be very useful tools to distinguish mixed seeds from different species and then avoid artificial adulteration and protect the interests of consumers.

4.3. Peony Seed Protein Profiles and Stress Resistance Analysis of Three Species. P. ostii "Fengdan," P. rockii, and P. lactiflora Pall "Hangshao" are important species that are used to produce peony seed oil $[3,5]$. In China, $P$. ostii "Fengdan" is mainly distributed in Anhui, Henan, Hubei, Shaanxi, and Sichuan provinces and $P$. rockii mainly grows in Gansu, Shaanxi, and Hubei provinces [32], while the distribution of $P$. lactiflora Pall "Hangshao" plants is extensive. Environmental factors in regional distribution greatly contribute to plant growth characteristics [8]. Therefore, it is widely accepted that $P$. rockii has high cold tolerance, $P$. ostii "Fengdan" has strong ability to resist heat, wet, and pathogens, and P. lactiflora Pall "Hangshao" also has high resistance to temperature and pathogen stress in many years of peony production. Heat shock proteins (HSPs) respond to stressful conditions, such as cold and oxidative stress [33]. As a molecular chaperone, DnaJ-like protein specifically regulates HSP70 [34]. Two heat shock proteins (34 and 38) were found only in $P$. rockii seeds, indicating that it has high cold tolerance, which was consistent with its geographical distribution and stress resistance potential. Moreover, two DEPs (Nos. 27 and 29) belonging to carbohydrate metabolism (100\%) were highly expressed in $P$. rockii seeds, resulting in strong carbohydrate metabolism. Soluble sugars, the products of carbohydrate metabolism, have been proved to enhance cold tolerance [35], which could be another supporting evidence for the high cold tolerance of $P$. rockii.

Delta 1-pyrroline-5-carboxylate synthetase (P5CS) is essential in proline biosynthesis and osmoregulation in plants [36]. Highly accumulated P5CS (Nos. 32 and 33), pathogen-related (No. 1), HSP (No. 4), and DnaJ-like proteins (No. 37) in P. ostii "Fengdan" seeds supported its strong ability to resist heat and pathogen stress. Moreover, there were eight SEPs in seeds of $P$. ostii "Fengdan" and five of them are stress related. Peptidyl-prolyl cis-trans isomerase (PPIase, No. 47) is involved in thermotolerance [37]. Glutathione S-transferase (GSTs, No. 50) is an evolutionarily conserved enzyme that is important in the detoxification of many xenobiotic compounds and is involved in oxidative stress [38]. Calcium is an important signaling molecule that can respond to various stress signals. Calcium-binding protein 45 (CML45, No. 52) plays an important role in insect, disease, and pathogen resistance [39]. Annexin I (No. 53) is a stress protein induced by heat, oxidative stress, and a sulfhydryl-reactive agent [40]. Oxylipins from the linoleate 9S-lipoxygenase (9-LOX, No. 54) pathway function in lateral root development and pathogen arrest [41]. To summarize briefly, the accumulated PPIase (No. 47) and annexin I (No. 53) in P. ostii "Fengdan" seeds may enhance its thermotolerance, while the enhanced CML45 (No. 52) and 9-LOX (No. 54) indicate its strong ability to resist pathogens and diseases.

One SEP of endochitinase was found in P. lactiflora Pall "Hangshao" seeds. Endochitinase may be associated with antagonistic activity against phytopathogenic fungi [42]. Thereby, it was deduced that P. lactiflora Pall "Hangshao" had high fungi stress tolerance. Eight DEPs were highly expressed in P. lactiflora Pall "Hangshao" seeds including one isoflavone $2^{\prime}$-hydroxylase (No. 48), two HSPs (Nos. 5 and 6), one GAPC-2 (No. 59), one phospholipase D delta (No. 60, involved in the nonhost resistance and basal defense) [43], and two auxin-related proteins (Nos. 58 and 61). In conclusion, the elevated accumulations of stressrelated proteins in $P$. lactiflora Pall "Hangshao" seeds showed its high resistance to temperature stress and pathogens.

4.4. Peony Seed Protein Characteristics, Function, and Extraction. Based on the Osborne classification (solubility in various solvents), proteins are divided into four groups: albumins, globulins, prolamins, and glutelins. Albumins and globulins are often functional enzymes, while glutelins and prolamins are storage proteins with different amino acid compositions [44]. Albumins and globulins account for $25 \%$ of total wheat seed proteins, while prolamins and glutelins are about $75 \%$ of the total [30]. Unlike protein composition in wheat seeds, albumins and globulins were dominant (75\%) in peony seeds, and its storage protein (prolamins and glutelins) content was about $25 \%$ of total proteins. This property (low storage protein content) of PSP is similar to pulse crops [45] and complementary to wheat seed proteins [30]. These differences may be caused by species specificity, seed structure, and metabolic diversity. A combination of peony, bean, and wheat protein may provide proper, essential, and relatively complete nutrition for humans. Plant proteins facilitate weight control, reduce blood pressure and cholesterol, and inhibit heart disease, stroke, and cancer [7]. Albumins and globulins also have some positive effects on human health due to their free radical-scavenging activity [46]. High levels of albumins and globulins in peony seeds, especially in $P$. ostii "Fengdan" seeds, showed their antioxidant capacity and potential medicinal values. Isoflavone $2^{\prime}$-hydroxylase participates in isoflavonoid biosynthesis. Isoflavones in soy protein have a beneficial role in obesity [47]. Evaluated isoflavone $2^{\prime}$-hydroxylase was also found in peony seeds, indicating that PSP might also be helpful for alleviating obesity.

Glucose produced is always absorbed into the blood, resulting in the elevated blood sugar. Therefore, $\alpha$-glucosidase is closely related with hyperglycemia. Many serious diseases are late complications of hyperglycemia, threatening people's health and life. $\alpha$-Glucosidase can hydrolyze the cleavage of 
glucose from disaccharides and oligosaccharides. Inhibition of $\alpha$-glucosidase activity can prevent these late complications by decreasing the postprandial rise in blood glucose [48]. Synthetic medicines, such as metformin, and acarbose are efficient $\alpha$-glucosidase inhibitors, but they also have serious side effects, like adverse gastrointestinal symptoms and hepatotoxicity $[49,50]$. Natural peptides, degradation products of natural proteins, are safe products with many biological activities including regulating blood glucose, protecting the liver, and immunoregulation [51]. In vitro hypoglycemic tests showed that PSP effectively inhibited the activity of $\alpha$-glucosidase. The glucosidase inhibition rate of PSP was about $22.6 \%-25.7 \%$ without significant differences among three peony species in the present study. Peptides extracted from Gypsophila oldhamiana and Momordica charantia also have $\alpha$-glucosidase inhibitory effects [51, 52]. The oral glucose tolerance test showed peptides from $M$. charantia produced a reduction of $25.50 \%, 39.62 \%$, and $41.74 \%$ in blood glucose levels after 1, 2, and 3 hours, respectively [51]. Similar with peptides from G. oldhamiana and $M$. charantia, PSP peptides showed potent inhibition of $\alpha$-glucosidase as expected. Conclusively, seed protein from all three peony species could potentially be applied in the food industry due to the favorable glucosidase inhibition activity.

Protein solubility is a vital parameter affecting the functionality and applicability of proteins [53]. The hydrolysis degree and protein solubility were the greatest in P. ostii "Fengdan" seeds, followed by $P$. rockii seeds, and the lowest in P. lactiflora Pall "Hangshao" seeds. Solubility of a protein product purified from Brassica napus was about 21.5\% [53]. Solubility of PSP was about $40 \%$ with a $60 \%$ degree of hydrolysis. All in all, results showed that PSP could be used as a food product with some beneficial functions and desirable physicochemical properties. Moreover, P. ostii "Fengdan" seeds are a better source for protein production than seeds of the other two species in terms of hydrolysis degree and protein solubility.

For high-quality PSP production, an appropriate, harmless, and reliable processing technology needs to be developed. Microwave-assisted extraction can increase protein yield [54]. We tried to combine microwave-assisted extraction and the alkali extraction and acid precipitation method together. Methods and conditions of protein extraction greatly affected the yield and protein characteristics. Based on a single-factor experiment and an $L_{9}\left(3^{4}\right)$ orthogonal experiment, an optimal protocol (solid-liquid ratio at $1: 35$, microwave power at 280 , microwave time $120 \mathrm{~s}$, and $\mathrm{pH}$ at 10.5) was developed, which is useful for the development of PSP.

\section{Conclusions}

In the present study, the physiological substance and protein profiles in seeds of $P$. ostii "Fengdan," P. rockii, and P. lactiflora Pall "Hangshao" were analyzed. A combination of one-way SDS-PAGE and 2-DE could be used to distinguish seeds of P. lactiflora Pall "Hangshao," P. ostii "Fengdan," and $P$. rockii. The albumin and globulin content was the greatest in P. ostii "Fengdan" seeds, followed by P. rockii seeds. Moreover, proteomic analysis by $2-\mathrm{DE}$ showed that the stress resistance potential of three peony species was related to those seed protein profiles, including HSP and thermotolerance-, stress-, and pathogen-related proteins. An in vitro test showed that PSP had high glucosidase inhibition activity. Above all, the seed proteomic profiles of three peony species supported their respective stress resistance characteristics and were very helpful for species identification. In addition, the PSP content was high in peony seed and the primary composition was albumin and globulin with good solubility and some potential function for the remission of hyperglycemia. Moreover, an optimal protocol of microwaveassisted alkali extraction was developed to produce PSP.

\section{Data Availability}

The data used to support the findings of this study are available from the corresponding author upon request.

\section{Conflicts of Interest}

The authors declare that they have no known competing financial interests or personal relationships that could have appeared to influence the work reported in this paper.

\section{Authors' Contributions}

XR performed the experiments, analyzed the data, and wrote the manuscript. YS and YX collected the samples, analyzed the proteomics, and revised the manuscript. YT performed the experiments and analyzed data. SW conceptualized and supervised the project. XZ designed the project and did the funding acquisition. All of the authors read and approved the final manuscript. XR, YS, and YX contributed equally to this work.

\section{Acknowledgments}

We would like to thank YT Shi and Dr. John Hugh Snyder for helping with revising the manuscript and improving the language of our manuscript, respectively. The work was supported by the grants from National Key R\&D Program of China (2019YFD1001500), Central Public-interest Scientific Institution Basal Research Fund (IVF-BRF2020020), Local Finance of Chengdu Agricultural Science \& Technology Center (NASC2020KR03), and China Agriculture Research System (CARS-21).

\section{Supplementary Materials}

Supplementary Table S1: volume of each reaction factor for determination of $\alpha$-glycosidase inhibition rate. Supplementary Table S2: analytical factors and levels for the protein extraction process in a single-factor experiment. Supplementary Table S3: analytical factors and levels for the protein extraction process in a $\mathrm{L}_{9}\left(3^{4}\right)$ orthogonal experiment. (Supplementary Materials)

\section{References}

[1] J. Su, C. Ma, C. Liu, C. Gao, R. Nie, and H. Wang, "Hypolipidemic activity of peony seed oil rich in $\alpha$-linolenic, is mediated through inhibition of lipogenesis and upregulation of fatty acid 
$\beta$-oxidation," Journal of Food Science, vol. 81, no. 4, pp. H1001-H1009, 2016.

[2] L. Gao, Y. Li, Z. Wang, G. Sun, X. Qi, and H. Mo, "Physicochemical characteristics and functionality of tree peony (Paeonia suffruticosa Andr.) seed protein," Food Chemistry, vol. 240, pp. 980-988, 2018.

[3] S. Li, R. Yuan, L. Chen et al., "Systematic qualitative and quantitative assessment of fatty acids in the seeds of 60 tree peony (Paeonia section Moutan DC.) cultivars by GC-MS," Food Chemistry, vol. 173, pp. 133-140, 2015.

[4] S. Yu, S. Du, J. Yuan, and Y. Hu, "Fatty acid profile in the seeds and seed tissues of Paeonia L. species as new oil plant resources," Scientific Reports, vol. 6, article 26944, 2016.

[5] C. Ning, Y. Jiang, J. Meng, C. Zhou, and J. Tao, "Herbaceous peony seed oil: a rich source of unsaturated fatty acids and $\gamma$ tocopherol," European Journal of Lipid Science and Technology, vol. 117, no. 4, pp. 532-542, 2015.

[6] C. He, Y. Peng, W. Xiao, H. Liu, and P. Xiao, "Determination of chemical variability of phenolic and monoterpene glycosides in the seeds of Paeonia species using HPLC and profiling analysis," Food Chemistry, vol. 138, no. 4, pp. 2108-2114, 2013.

[7] W. J. Craig, "Nutrition concerns and health effects of vegetarian diets," Nutrition in Clinical Practice, vol. 25, no. 6, pp. 613620, 2010.

[8] K. Zhang, Y. Zhang, C. Zhou et al., "Impact of climate factors on future distributions of Paeonia ostii across China estimated by MaxEnt," Ecological Informatics, vol. 50, pp. 62-67, 2019.

[9] K. L. Chee, H. K. Ling, and M. K. Ayob, "Optimization of trypsin-assisted extraction, physico-chemical characterization, nutritional qualities and functionalities of palm kernel cake protein," Lwt-Food Science and Technology, vol. 46, no. 2, pp. 419-427, 2012.

[10] WHO, "Energy and protein requirements," Report of a Joint FAO/WHO/UNU Expert Consultation, WHO Technical Report Series 724, World Health Organization, Geneva, 1985.

[11] S. A. Malomo and R. E. Aluko, "Conversion of a low protein hemp seed meal into a functional protein concentrate through enzymatic digestion of fibre coupled with membrane ultrafiltration," Innovative Food Science \& Emerging Technologies, vol. 31, pp. 151-159, 2015.

[12] B. Ling, B. Zhang, R. Li, and S. J. Wang, "Nutritional quality, functional properties, bioactivity, and microstructure of defatted pistachio kernel flour," Journal of the American Oil Chemists Society, vol. 93, no. 5, pp. 689-699, 2016.

[13] S. Mundi and R. E. Aluko, "Physicochemical and functional properties of kidney bean albumin and globulin protein fractions," Food Research International, vol. 48, no. 1, pp. 299306, 2012.

[14] S. Kumar, S. Narwal, V. Kumar, and O. Prakash, " $\alpha$-Glucosidase inhibitors from plants: a natural approach to treat diabetes," Pharmacognosy Reviews, vol. 5, no. 9, pp. 19-29, 2011.

[15] X. J. Wang, H. Y. Liang, D. L. Guo et al., "Integrated analysis of transcriptomic and proteomic data from tree peony ( $P$. ostii) seeds reveals key developmental stages and candidate genes related to oil biosynthesis and fatty acid metabolism," Horticulture Research, vol. 6, 2019.

[16] X. X. Ren, J. Q. Xue, S. L. Wang et al., "Proteomic analysis of tree peony (Paeonia ostii 'Feng Dan') seed germination affected by low temperature," Journal of Plant Physiology, vol. 224, pp. 56-67, 2018.
[17] D. He, X. Y. Lou, S. L. He et al., "Isobaric tags for relative and absolute quantitation-based quantitative proteomics analysis provides novel insights into the mechanism of crossincompatibility between tree peony and herbaceous peony," Functional Plant Biology, vol. 46, no. 5, pp. 417-427, 2019.

[18] D. Q. Zhao, S. J. Gong, Z. J. Hao, J. S. Meng, and J. Tao, "Quantitative proteomics analysis of herbaceous peony in response to paclobutrazol inhibition of lateral branching," International Journal of Molecular Sciences, vol. 16, no. 10, pp. 24332 24352, 2015.

[19] Y. X. Zhang, D. Yu, X. L. Tian, C. Y. Liu, S. P. Gai, and G. S. Zheng, "Differential expression proteins associated with bud dormancy release during chilling treatment of tree peony (Paeonia suffruticosa)," Plant Biology, vol. 17, no. 1, pp. 114122, 2015.

[20] N. Zeng, Z. Yang, Z. Zhang, L. Hu, and L. Chen, "Comparative transcriptome combined with proteome analyses revealed key factors involved in Alfalfa (Medicago sativa) response to waterlogging stress," International Journal of Molecular Sciences, vol. 20, 2019.

[21] F. Liu, Y. Meng, K. He et al., "Comparative analysis of proteomic and metabolomic profiles of different species of Paris," Journal of Proteomics, vol. 200, pp. 11-27, 2019.

[22] G. Branlard, M. Dardevet, R. Saccomano, F. Lagoutte, and J. Gourdon, "Genetic diversity of wheat storage proteins and bread wheat quality," Euphytica, vol. 119, no. 1/2, pp. 59-67, 2001.

[23] S. Wang, K. Wang, G. Chen et al., "Molecular characterization of LMW-GS genes in Brachypodium distachyon L. reveals highly conserved Glu-3 loci in Triticum and related species," BMC Plant Biology, vol. 12, p. 221, 2012.

[24] X. Y. Han, L. S. Wang, Q. Y. Shu, Z. A. Liu, S. X. Xu, and T. Tetsumura, "Molecular characterization of tree peony germplasm using sequence-related amplified polymorphism markers," Biochemical Genetics, vol. 46, no. 3-4, pp. 162-179, 2008.

[25] Z. Gao, J. Wu, Z.'a. Liu, L. Wang, H. Ren, and Q. Shu, "Rapid microsatellite development for tree peony and its implications," BMC Genomics, vol. 14, no. 1, p. 886, 2013.

[26] X. Wei, J. Xue, S. Wang et al., "Fatty acid analysis in the seeds of 50 Paeonia ostii individuals from the same population," Journal of Integrative Agriculture, vol. 17, no. 8, pp. 17581767, 2018.

[27] M. He, C. Zhu, K. Dong et al., "Comparative proteome analysis of embryo and endosperm reveals central differential expression proteins involved in wheat seed germination," BMC Plant Biology, vol. 15, 2015.

[28] P. M. Nielsen, D. Petersen, and C. Dambmann, "Improved method for determining food protein degree of hydrolysis," Journal of Food Science, vol. 66, no. 5, pp. 642-646, 2001.

[29] I. Karaye, A. Aliero, S. Muhammad, and L. Bilbis, "Evaluation of nutrient and anti-nutrient contents of selected Nigerian cucurbits seeds," Research Journal of Pharmaceutical, Biological and Chemical Sciences, vol. 4, pp. 137-142, 2013.

[30] Z. Šramková, E. Gregová, and E. Šturdík, "Chemical composition and nutritional quality of wheat grain," Acta Chimica Slovaca, vol. 2, pp. 115-138, 2009.

[31] H. Thiellement, N. Bahrman, C. Damerval et al., "Proteomics for genetic and physiological studies in plants," Electrophoresis, vol. 20, no. 10, pp. 2013-2026, 1999. 
[32] Z. Zhou, "Taxonomy, geographic distribution and ecological habitats of tree peonies," Genetic Resources and Crop Evolution, vol. 53, no. 1, pp. 11-22, 2006.

[33] R. Morimoto, "Cells in stress: transcriptional activation of heat shock genes," Science, vol. 259, no. 5100, pp. 1409-1410, 1993.

[34] D. M. Cyr, T. Langer, and M. G. Douglas, "DnaJ-like proteins: molecular chaperones and specific regulators of Hsp70," Trends in Biochemical Sciences, vol. 19, no. 4, pp. 176-181, 1994.

[35] L. P. Tarkowski and W. Van den Ende, "Cold tolerance triggered by soluble sugars: a multifaceted countermeasure," Frontiers in Plant Science, vol. 6, 2015.

[36] A. Hmida-Sayari, R. Gargouri-Bouzid, A. Bidani, L. Jaoua, A. Savouré, and S. Jaoua, "Overexpression of $\Delta 1$-pyrroline-5carboxylate synthetase increases proline production and confers salt tolerance in transgenic potato plants," Plant Science, vol. 169, no. 4, pp. 746-752, 2005.

[37] G. Kaur, S. Singh, T. Dutta et al., "The peptidyl-prolyl cis-trans isomerase activity of the wheat cyclophilin, TaCypA-1, is essential for inducing thermotolerance in Escherichia coli," Biochimie Open, vol. 2, pp. 9-15, 2015.

[38] E. A. Veal, W. M. Toone, N. Jones, and B. A. Morgan, "Distinct roles for glutathione S-transferases in the oxidative stress response in Schizosaccharomyces pombe," Journal of Biological Chemistry, vol. 277, no. 38, pp. 35523-35531, 2002.

[39] A. S. N. Reddy, G. S. Ali, H. Celesnik, and I. S. Day, "Coping with stresses: roles of calcium- and calcium/calmodulin-regulated gene expression," The Plant Cell, vol. 23, pp. 20102032, 2012.

[40] H. J. Rhee, G. Y. Kim, J. W. Huh, S. W. Kim, and D. S. Na, "Annexin I is a stress protein induced by heat, oxidative stress and a sulfhydryl-reactive agent," European Journal of Biochemistry, vol. 267, no. 11, pp. 3220-3225, 2000.

[41] T. Vellosillo, M. Martínez, M. A. López et al., "Oxylipins produced by the 9-lipoxygenase pathway in Arabidopsis regulate lateral root development and defense responses through a specific signaling cascade," The Plant Cell, vol. 19, no. 3, pp. 831-846, 2007.

[42] L. A. C. J. De, A. Hidalgo-Gallego, J. M. Lora, T. Benitez, J. A. Pintor-Toro, and A. Llobell, "Isolation and characterization of three chitinases from Trichoderma harzianum," European Journal of Biochemistry, vol. 206, pp. 859-867, 1992.

[43] F. Pinosa, N. Buhot, M. Kwaaitaal et al., "Arabidopsis phospholipase $\mathrm{D} \delta$ is involved in basal defense and nonhost resistance to powdery mildew fungi," Plant Physiology, vol. 163, no. 2, pp. 896-906, 2013.

[44] L. Gao, A. Wang, X. Li et al., "Wheat quality related differential expressions of albumins and globulins revealed by twodimensional difference gel electrophoresis (2-D DIGE)," Journal of Proteomics, vol. 73, no. 2, pp. 279-296, 2009.

[45] F. Roy, J. I. Boye, and B. K. Simpson, "Bioactive proteins and peptides in pulse crops: pea, chickpea and lentil," Food Research International, vol. 43, no. 2, pp. 432-442, 2010.

[46] Q. Deng, L. Wang, F. Wei et al., "Functional properties of protein isolates, globulin and albumin extracted from Ginkgo biloba seeds," Food Chemistry, vol. 124, no. 4, pp. 1458-1465, 2011.

[47] M. T. Velasquez and S. J. Bhathena, "Role of dietary soy protein in obesity," International Journal of Medical Sciences, vol. 4, no. 2, pp. 72-82, 2007.
[48] H. B. B. Ag, "Pharmacology of $\alpha$-glucosidase inhibition," European Journal of Clinical Investigation, vol. 24, pp. 3-10, 1994.

[49] D. Rosas-Ramirez, S. Escandon-Rivera, and R. PeredaMiranda, "Morning glory resin glycosides as $\alpha$-glucosidase inhibitors: in vitro and in silico analysis," Phytochemistry, vol. 148, pp. 39-47, 2018.

[50] X. M. Zheng, H. Q. Sun, L. R. Wu, X. R. Kong, Q. Y. Song, and Z. Y. Zhu, "Structural characterization and inhibition on $\alpha$ glucosidase of the polysaccharides from fruiting bodies and mycelia of Pleurotus eryngii," International Journal of Biological Macromolecules, vol. 156, pp. 1512-1519, 2020.

[51] X. Yuan, X. Gu, and J. Tang, "Purification and characterisation of a hypoglycemic peptide from Momordica charantia L. Var. abbreviata Ser," Food Chemistry, vol. 111, no. 2, pp. 415-420, 2008.

[52] J. Luo, X. Wang, L. Ma, and L. Kong, "Gypsophin: a novel $\alpha$ glucosidase inhibitory cyclic peptide from the roots of Gypsophila oldhamiana," Bioorganic \& Medicinal Chemistry Letters, vol. 17, no. 16, pp. 4460-4463, 2007.

[53] A. Rehder, A. M. Sulewska, K. E. Markedal, S. Sørensen, and J. C. Sørensen, "Solubility of a cruciferin-rich protein product purified from rapeseed pressed cake (Brassica napusL.) by an aqueous processing method," International Journal of Food Science \& Technology, vol. 52, no. 7, pp. 1653-1659, 2017.

[54] S. Phongthai, S.-T. Lim, and S. Rawdkuen, "Optimization of microwave-assisted extraction of rice bran protein and its hydrolysates properties," Journal of Cereal Science, vol. 70, pp. 146-154, 2016. 